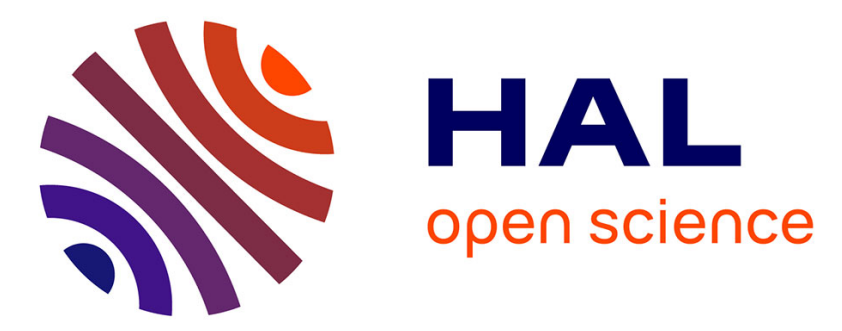

\title{
La philosophie shicite face au problème du mal : essais de théodicée chez Mīr Dāmād (m. 1040/1631) et deux de ses élèves
}

Mathieu Terrier

\section{- To cite this version:}

Mathieu Terrier. La philosophie shicite face au problème du mal: essais de théodicée chez Mīr Dāmād (m. 1040/1631) et deux de ses élèves. Oriens, 2021, 49 (3-4), pp.269-317. 10.1163/1877837212340006 . halshs-03502414

\section{HAL Id: halshs-03502414 \\ https://shs.hal.science/halshs-03502414}

Submitted on 4 Jan 2022

HAL is a multi-disciplinary open access archive for the deposit and dissemination of scientific research documents, whether they are published or not. The documents may come from teaching and research institutions in France or abroad, or from public or private research centers.
L'archive ouverte pluridisciplinaire HAL, est destinée au dépôt et à la diffusion de documents scientifiques de niveau recherche, publiés ou non, émanant des établissements d'enseignement et de recherche français ou étrangers, des laboratoires publics ou privés. 


\title{
La philosophie shi'ite face au problème du mal :
}

essais de théodicée chez Mīr Dāmād (m. 1040/1631) et deux de ses élèves

\author{
Mathieu Terrier \\ CNRS, PSL, LEM, Paris \\ met_terrier@yahoo.fr
}

\begin{abstract}
The problem of the goodness of God, the freedom of man and the origin of Evil, i.e. theodicy, proves to be particularly acute in Twelver Shici Islam, because of the historical awareness of evil within the community and of the fundamental dualism, metaphysical as well as moral, of the doctrine. However, this problem was the subject of various essays by Iranian Shici philosophers of Neoplatonic inspiration, trying to harmonize the teachings of the Shici tradition (i.e. the hadit ts attributed to the Impeccable imams) with the arguments of the Avicennian philosophy. The first part of the article focuses in detail on the works of the philosopher, theologian and lawyer Mīr Dāmād (m. 1041/1631). His reflections on the problem are not collected in a single book, as they are in Leibniz, but scattered in works belonging to different fields (fiqh, kalām, or philosophy per se), in Arabic or in Persian. He deals successively with the problem of human freedom (qadar) versus divine determinism (ğabr); with the Imami notion of badā', i.e. the apparent change of the divine Will in the course of history; with Good and Evil with regard to the ontological categories of essence (dِāt), accident ('arạ̣), existence (wuğūd), and non-existence ('adam); with the execution of eschatological threats and the punishment of the damned thus embracing all the dimensions of the problem and phenomenon of evil. The second part of the article considers some logical and unexpected developments of Mīr Dāmād's theses in the works of two of his students, Mullā Šamsā Gīlānī (m. 1064/1654), in a brief epistle on perfection, and Quṭb al-Dīn Aškevarī (m. between 1088/1677 and 1095/1684), in a monumental history of universal wisdom. This should make appear that the problem of Evil was a powerful catalyst for the emergence of a "Shici philosophy" in the $11^{\text {th }} / 17^{\text {th }}$ century.
\end{abstract}

\section{Keywords}

Mīr Dāmād, Mullā Šamsā Gīlānī, Quṭb al-Dīn Aškevarī, theodicy, evil, human freedom, Twelver Shi'ism, Neoplatonism

\section{Résumé}

Le problème de la bonté de Dieu, de la liberté de l'homme et de l'origine du mal, c'est-à-dire de la théodicée, s'avère particulièrement délicat dans l'islam shiite duodécimain, du fait de la conscience historique du mal dans la communauté et du dualisme foncier, moral et métaphysique, de la doctrine. Ce problème fit pourtant l'objet de véritables essais de théodicée chez des philosophes shi'ites iraniens d'inspiration néoplatonicienne, 
s'efforçant de concilier les enseignements de la tradition shi'ite (les ḥadīts attribués aux imâms impeccables) et les arguments de la philosophie avicennienne. La première partie de l'article se concentre sur l'œuvre du philosophe, théologien et juriste Mīr Dāmād (m. 1041/1631). Ses réflexions sur le problème ne sont pas rassemblées dans un même livre, à la différence de Leibniz, mais disséminées dans des ouvrages de différents domaines (fiqh, kalām, philosophie per se), en arabe et en persan. Il traite successivement du problème de la liberté humaine (qadar) vs le déterminisme divin ( ğabr); de la notion imâmite de badā', le changement apparent de la Volonté divine dans le cours de l'histoire; du bien et du mal au regard des catégories ontologiques de l'essence ( $\underline{d} \bar{a} t)$ et de l'accident ('arạ̣), de l'existence (wuğūud) et de l'inexistence ('adam); de l'exécution des menaces eschatologiques et du châtiment des damnés - embrassant ainsi toutes les dimensions du problème et du phénomène du mal. La seconde partie de l'article étudie les prolongements, à la fois cohérents et inattendus, des thèses de Mīr Dāmād chez deux de ses élèves, Mullā Šamsā Gīlānī (m. 1064/1654), dans une épître sur la perfection, et Quṭb al-Dīn Aškevarī (m. entre 1088/1677 et 1095/1684), dans une histoire de la sagesse universelle. Le problème du mal apparaît ainsi comme un facteur d'émergence d'une authentique «philosophie shicite » au XI $/ \mathrm{XVII}^{\mathrm{e}}$ siècle.

\section{Mots-clés}

Mīr Dāmād, Mullā Šamsā Gīlānī, Quṭb al-Dīn Aškevarī, théodicée, mal, liberté humaine, shicisme duodécimain, néoplatonisme

Le problème du mal, écrivait Paul Ricœur, est un «défi à la théologie et à la philosophie ». La théodicée, entreprise indissociablement théologique et philosophique, tente de relever ce défi en rendant compte ensemble de trois propositions: Dieu est tout-puissant; Dieu est infiniment bon; le mal existe apparemment. Cette étude voudrait montrer comment le problème du mal et le projet de théodicée ont contribué à la vivacité de la philosophie en Islam et particulièrement à l'émergence d'une "philosophie shi ite » dans l'Iran safavide du XI $/ \mathrm{XVII}^{\mathrm{e}}$ siècle.

Le projet de théodicée est loin d'aller de soi dans le cadre de pensée de l'islam shi'ite imâmite ou duodécimain. D'abord, le Dieu du Coran semble posséder des caractères ambivalents : ses attributs essentiels sont la Science ( 'ilm), la Puissance (qudra) et la Justice ('adl) ; il est le Sage (al-ḥakìm), le Clément (al-ḥalīm), le Miséricordieux (al-ǵaffār), mais aussi le Tout-Puissant (al-'azīz), le Contraignant (al-ğabbār) et l'Orgueilleux (almutakabbir); Il « égare qui Il veut et guide qui Il veut » (Cor. 14:4); Il rétribue les croyants par des récompenses

\footnotetext{
${ }^{1}$ Paul Ricœur, Le mal. Un défi à la philosophie et à la théologie, Genève, Labor et fides, 2004, p. 39.
} 
éternelles et les incroyants par un châtiment éternel. Ces caractères ambivalents semblent encore accentués dans le corpus de hadīț attribués aux imâms shicites, considéré comme d'origine révélée au même titre ou presque que le Coran ${ }^{2}$. La doctrine contenue dans ces traditions, que l'on peut qualifier de doctrine originelle du shi'isme ${ }^{3}$, se caractérise par une pensée duelle, axée sur la distinction entre l'exotérique (zāhir) et l'ésotérique ( bāțin), et une pensée dualiste, axée sur l'opposition du vrai identifié au bien et du faux identifié au mal' ${ }^{4}$ Selon un hadịt attribué aux imâms et souvent commenté, Dieu créa d'abord l'Intelligence ( 'aqI), qui reçut

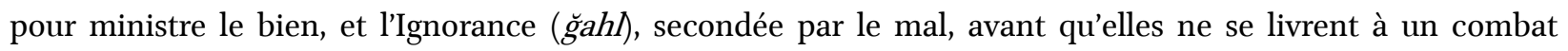
perpétuel, chacune à la tête de soixante-douze armées de puissances symboliques ${ }^{5}$. Un hadịt affirme même que Dieu créa originellement le mal ( ̌̌arr) comme le bien $(\text { hayr })^{6}$. Ce dualisme de la doctrine imâmite originelle est sans nul doute lié à la mémoire historique des shi'ites et à l'historiosophie, ou « sagesse de l'histoire », élaborée sur elle : le mal est d'abord ce qu'ont subi les « gens de la famille du Prophète » (ahl al-bayt) - 'Alī b. Abī Ṭālib (m. 40/661), cousin et gendre de Muhammad, son épouse Fāțima et leur descendance - et ce qu'ont commis leurs adversaires historiques - à commencer par les trois premiers califes et tous les gouvernants des dynasties omeyyade et 'abbasside. En seconde instance, le mal est le châtiment promis à ces adversaires, d'abord lors du retour du douzième imâm à la fin des temps - avec une première résurrection corporelle, réservée à un petit nombre d'amis et d'ennemis de Dieu, appelée rağ‘ $a-$-, puis après la Grande Résurrection. Il existe donc, d'abord, un Mal radical et un péché originel d'ordre historique et mémoriel ; et, dans un second temps, un mal pour le Bien, un mal rendu réparateur du mal subi ${ }^{7}$. En ayant à l'esprit ce dualisme fondamental de la doctrine imâmite, on saisira d'emblée la difficulté du projet de théodicée dans ce système de pensée. Comment exempter Dieu de tout mal sans perdre le sens de l'imâmologie et de l'historiosophie shi'ites?

Par ailleurs, les philosophes shicites de l'Iran safavide étaient imprégnés de néoplatonisme, lecteurs de la Théologie dite d'Aristote (Utūlūğiyā Arisțātālīss) et héritiers de l'avicennisme. Or dans cette tradition

\footnotetext{
${ }^{2}$ Les plus anciens recueils de traditions imâmites conservés datent du IV $/ \mathrm{X}^{\mathrm{e}}$ siècle : Șaffār al-Qummī (m. 29o/902-3), Bașā’ir al-darağăt, éd. 'Alīreḍā Zakīzādeh Renānī, 2 vol. (Qom : Wuṭūq, 1391 h.s./2012-3) ; Muḥammad b. Ya'qūb al-Kulaynī (m. 329/940-1), Kitāb al-Kāfì (Ușül al-Kāfi, éd. s. n. (Beyrouth : Mu'assasat al-a'lamī li-l-mațbū'āt, 1426/2005) ; Furū' al-Käfi, éd. s. n. (Beyrouth : Mu'assasat al-a'lamī li-l-mațbūât, 1426/2005)). La dernière grande compilation, reprenant une large part du corpus le plus ancien, est l'œuvre monumentale de Muhạmmad Bāqir al-Mağlisī (m. 1111/1699), Bịhār alanwār, éd. s.n., 111 vol. (Beyrouth : Dār ihyā̄' al-turāt al-'arabī, 1403/1983).

${ }^{3}$ Le shi'isme imâmite connut, après l'« Occultation majeure » (al-gaayba al-kubrā) du douzième imâm (329/940-1) et à partir de l'époque bouyide (334-447/945-1055), une réforme rationalisante atténuant fortement les aspects ésotériques de la doctrine et substituant à l'autorité charismatique de l'imâm l'autorité institutionnelle du juriste-théologien (faqīh, muğtahid). Sur cette évolution historique complexe, voir Mohammad Ali Amir-Moezzi, La preuve de Dieu. La mystique shi'ite à travers l'œuvre d'al-Kulaynî (IX $X^{e} X^{e}$ siècle)(Paris : Le Cerf, 2018), 271-309.

${ }^{4}$ Voir Mohammad Ali Amir-Moezzi et Christian Jambet, Qu'est-ce que le shi'isme ?(Paris : Fayard, 2004), 36-40.

${ }^{5}$ Al-Kulaynī, Ușūl al-Kāfì, éd. s. n. (Beyrouth : Mu'assasat al-alamī li-l-mațbū'āt, 1426/2005), Kitāb al-'aql wa-l-ğahl, 16-17, ḥ. 14. Sur cette tradition, voir Mohammad Ali Amir-Moezzi, Le guide divin dans le shîissme originel. Aux sources de

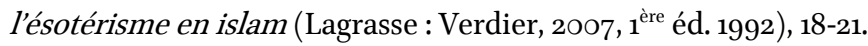

${ }^{6}$ Al-Kulaynī, Ușūl al-Kāfi, Kitāb al-tawḥìd, bāb al-ȟayr wa l-šarr, 88, ḥ. 1-3; 'Alī b. Muḥammad al-Barqī, Kitāa al-Mahāsin, éd. Mahdī al-Rağā̄ì, 2 vol. (Téhéran : al-Mağma' al-ālamī li-ahl al-bayt, 1432/2011), vol. 1, 440, ḥ. 1 ; tradition citée infra.

${ }^{7}$ Voir là-dessus Mathieu Terrier, « Le combat sacré des vaincus de l'histoire : expérience et représentation du jihăd dans le shi'isme imamite ancien », Journal Asiatique 305.1 (2017), 23-31. Voir aussi, sur cette dialectique du mal subi et du mal rendu, Sepideh Parsapajouh, « Le mal subi, le mal rendu. Une lecture anthropologique des pratiques de lamentations et de malédictions dans le shi isme populaire iranien », dans ce dossier.
} 
philosophique, Dieu est identifié au Bien pur et le Bien pur à l'Être même dont tout procède et à quoi tout revient. Certes, Avicenne avait jugé utile de procéder dans ce cadre de pensée à une théodicée fondée sur la notion de Providence ( ínāya), entreprise partiellement reprise par al-Ġazālī (m. 505/1111) et critiquée par Fahr al-Dīn al-Rāzī (m. 6o6/1209) dans le monde sunnite ${ }^{8}$. Comment, dans un tel système, rendre compte de la mémoire shicite et de la consistance substantielle du mal affirmée par les traditions?

En somme, comment concilier le dualisme de la tradition imâmite et l'identification néoplatonicienne de l'Être au Bien ? Tel est l'enjeu du problème de la théodicée chez les penseurs shi'ites du XI $/ \mathrm{XVII}^{\mathrm{e}}$ siècle. Pour l'étudier, nous nous pencherons sur l'œuvre de Mīr Dāmād (m. 1041/1631), à la fois maitre de philosophie et juriste-théologien faisant autorité (muğtahid) dans l'appareil d'État safavide et sa capitale Ispahan'. Ses écrits sur le problème ne sont pas rassemblés dans un traité systématique mais disséminés dans plusieurs ouvrages, en arabe et en persan, développant des perspectives différentes et adressés à des publics différents, plus ou moins initiés à la philosophie. Nous aurions pu mener une comparaison de sa pensée sur le sujet avec celle de son contemporain, le plus illustre philosophe de l'Iran safavide, Mullā Șadrāa ${ }^{10}$, mais nos recherches nous ont conduit à explorer les prolongements des propositions de Mīr Dāmād chez deux de ses élèves encore méconnus, Mullā Šamsā Gīlānī (m. 1064/1654) et Quṭb al-Dīn Aškevarī (m. entre 1088/1677 et 1095/1684). Les pages suivantes examineront donc comment ces trois penseurs ont affronté le problème du mal et celui, connexe, de la liberté humaine, à la fois comme une aporie à surmonter par la connaissance rationnelle et comme une question à résoudre dans le respect de la tradition scripturaire.

\section{Essais de théodicée de Mīr Dāmād}

En rapprochant des textes dispersés dans l'œuvre de Mīr Dāmād, nous montrerons comment il s'efforça d'expliquer et de justifier, conformément à la sagesse de Dieu, l'existence du mal dans ses cinq dimensions fondamentales : métaphysique (l'imperfection, l'inexistence ou la privation), physique (la souffrance, la maladie, la mort), moral (toute injustice commise par l'homme), historique (l'injustice subie par les imâms et leurs shicites) et eschatologique (le châtiment des damnés et la vengeance contre les ennemis des imâms).

\section{La Sagesse de Dieu et les principes de la théodicée}

\footnotetext{
${ }^{8}$ Eric Ormsby, Theodicy in Islamic Thought: the Dispute over al-Ghazali's Best of All Possible Worlds (Princeton: Princeton University Press, 1984); Ayman Shihadeh, «Avicenna's Theodicy and al-Rāzīs Anti-Theodicy », Intellectual History of the Islamicate World 7 (2019), 61-84.

${ }^{9}$ Sur cette double dimension, voir Mathieu Terrier, «Mīr Dāmād (m. 1041/1631), philosophe et mujtahid. Autorité spirituelle et autorité juridique en Iran safavide shīite », Studia Islamica 113 (2018) : 121-165.

${ }^{10}$ Sur le problème du mal chez Mullā Șadrā, voir Sajjad Rizvi, « Considering Divine Providence in Mullā Ṣadrā Šīāzī (d. 1045/1636): The Problem of Evil, Theodicy, and the Divine Eros », dans ce dossier. Sur le problème du mal chez son élève et gendre Muhsin al-Fayḍ al-Kāšānī, voir Mathieu Terrier, « Anthropogonie et eschatologie dans l'œuvre de Muhsin Fayḍ Kâshânî : l'ésotérisme shî‘ite entre tradition et syncrétisme », dans Mohammad Ali Amir-Moezzi (dir.), L'ésotérisme shīite, ses racines et ses prolongements (Turnhout : Brepols, 2016), 743-780.
} 
Mīr Dāmād donne une première approche du problème du mal dans l'introduction de son Šāri' alnağāt (La Voie du salut). Il s'agit d'une somme juridique ou d'un «traité pratique » juridique (risāla 'amaliyya) destiné à régler les obligations cultuelles ( íbādāt) du commun des croyants, rédigé en persan sans doute pour atteindre un plus large lectorat, dans lequel on est étonné de trouver d'emblée un développement philosophique ${ }^{11}$. C'est en effet le concept de sagesse divine (hikma) qui conduit à un premier argument relevant de la théodicée :

La sagesse a deux sens. Premièrement, c'est la plus excellente des sciences du plus excellent des objets de science. Dieu Très-Haut connaît, de Sa science parfaite et complète qui est la plus excellente des sciences, le fond de Son essence qui est le plus excellent des objets de science. Hormis Lui, nul ne possède cette science. Deuxièmement, [la sagesse] est ce que [fait] l'auteur de l'action libre (muhtār), ferme et soignée, comprenant utilité, finalité, intérêt et bénéfice. Les intelligences des plus éminents intellectuels demeurent perplexes, stupéfaites et interdites quand elles cherchent à saisir la fermeté, l'habileté, les finalités, les avantages, les intérêts, les bénéfices, la direction des biens et des bénédictions compris dans chaque acte de l'Agent absolu. Par suite, le Sage véritable, dans les deux sens du terme, n'est nul autre que le Provident, le Nécessaire par soi (...). Tout ce qui reçoit l'existence dans le monde de la possibilité est subordonné au Décret et à la Détermination de Dieu (qậā’'va qadar-i ilāhî̀). Les biens du monde dépendent de la Volonté [divine] et entrent dans le Décret par essence ( bi l-dāt) ; les maux, eux, n'y entrent que par accident (bi l-'arạ̣), en tant qu'ils sont les concomitants (lavāzim) de biens innombrables et d'intérêts supérieurs. La Grâce de Dieu, Sa Sagesse, Sa Miséricorde, Sa Providence et Sa Justice, qui sont à l'origine de la responsabilité des créatures (taklîf-i bandagān), exigent que l'accomplissement de bonnes et belles actions, comme l'évitement d'actes mauvais et laids, soient le fait de leur volonté (irāda) et de leur choix

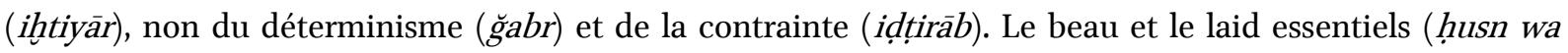
$q a b h+\underline{i} \mathbf{d} \bar{a} t \bar{\imath})$ des actions et des œuvres dépendent de l'impératif et de l'interdit divins ${ }^{12}$.

La sagesse divine, comme la sagesse humaine dont elle est le modèle, possède une dimension théorétique et une dimension pratique. Résoudre le problème de l'existence apparente du mal exige de comprendre la sagesse pratique du Créateur, mais ceci dépasse a priori les capacités de la raison humaine. Pour appréhender la Providence divine, soit le gouvernement de toute chose selon les meilleures fins, il faut d'abord reconnaître que la vraie Sagesse n'appartient qu'à Dieu et que la philosophie n'est donc, conformément à son étymologie grecque, que recherche, désir et non possession de la sagesse. Il faut également admettre que tout existant est soumis au Décret (qậā) et à la Détermination (qadar), correspondant à deux niveaux du

\footnotetext{
${ }^{11}$ Sur cette œuvre, voir Terrier, « Mīr Dāmād (m. 1041/1631), philosophe et mujtahid», 133-143.

${ }^{12}$ Mīr Dāmād, Muqaddima Risāla Šāri' al-nağāt, dans Muṣannafāt Mīr Dāmād, éd. 'Alī Nūrānī, vol. 1 (Téhéran : Anğuman-i ātāar wa mafāhirir-i farhangī, 1381 h.s./2003, 568-580), 571.
} 
gouvernement divin : le premier au monde de l'Intellect, synthétique et méta-temporel, le second au monde de l'Âme, traduction analytique et temporelle du précédent ${ }^{13}$.

Ce passage formule de manière concise trois principes fondamentaux de la théodicée que l'on retrouvera développés dans les œuvres philosophiques de Mīr Dāmād :1) Les biens du monde sont les objets de la Volonté divine et entrent dans le Décret par essence ; les maux ne sont pas voulus par Dieu pour euxmêmes mais sont les concomitants de bienfaits supérieurs ; ils n'entrent donc dans le Décret que par accident. 2) Conformément à la Sagesse et à la Justice de Dieu, l'imputabilité humaine doit aller de pair avec le librearbitre, les actions bonnes ou mauvaises de l'homme doivent donc être libres et non déterminées pour recevoir une juste rétribution - ce qui vaut ici-bas d'un point de vue juridique comme au Jugement Dernier d'un point de vue théologique. Sur ce dernier point, Mīr Dāmād rejoint l'idée fondamentale de la théologie rationaliste des mu'tazilites : Dieu ne serait pas juste s'il jugeait un homme pour ce qu'il a été contraint et non libre de faire. 3) La beauté ou la laideur morale de l'action humaine dépend de l'impératif et de l'interdit divins : ce n'est pas parce qu'une action est belle qu'elle est ordonnée par Dieu, mais parce qu'elle est ordonnée par Dieu qu'elle est belle ; tout comme ce n'est pas parce qu'une action est laide qu'elle est interdite par Dieu, mais parce qu'elle est interdite par Dieu qu'elle est laide. À l'inverse du précédent, ce principe s'oppose au mu'tazilisme et s'accorde avec la théologie ash'arite; il confirme que la sagesse pratique de De Dieu est au-delà de l'entendement humain. Il demeure donc une tension entre, d'une part, l'idée d'une Volonté divine absolument bonne et toutepuissante et, d'autre part, l'affirmation du libre arbitre, de la possibilité de l'action mauvaise et d'un mal imputable à l'homme.

\section{Le mal moral et la création des actes}

Le problème de la création des actes humains, de leur attribution à la Volonté divine ou au libre arbitre de l'homme, est discuté par Mīr Dāmād dans un ouvrage de théologie dialectique, rédigé en arabe avant 1025/1616, intitulé Risālat al-Īqāāāt fỉ halq al-a'māl (Épître des éveils sur la création des actes). L'argumentation $\mathrm{du}$ maître y conjugue l'argumentation rationnelle (al-ma'qu $\bar{u})$ et les citations traditionnelles (al-manqū $)$, suivant une voie médiane entre deux tendances rivales de l'imâmisme : une théologie fondée sur l'autorité de la raison et une théologie fondée sur des traditions scripturaires souvent ésotériques et non rationnelles. Rappelons que le problème de la liberté ou du déterminisme fut à l'époque umayyade le premier motif de dispute théologique en Islam, avec des implications politiques évidentes ${ }^{14}$; qu'il se cristallisa, à l'époque

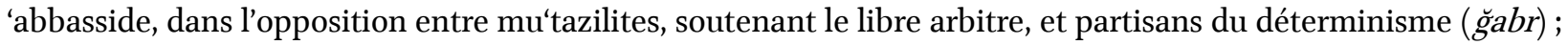
puis qu'il donna lieu dans l'ash 'arisme à la solution de l'« acquisition» (kasb) des actes. Les shi'ites imâmites attribuent à leur sixième imâm, Ğa'far al-Ṣādiq (m. 148/765) la formulation d'une troisième voie : « Ni

\footnotetext{
${ }^{13}$ Sur cette distinction d'origine coranique, voir Morgan Guiraud, «Destin», dans Mohammad Ali Amir-Moezzi (dir.), Dictionnaire du Coran (Paris : Robert Laffont, 2007), 209-212.

${ }^{14}$ Joseph Van Ess, « Kadariyya », $E F$, IV, p. 384-388; Hasan Qasim Murad, «Jabr and Qadar in Early Islam : A Reappraisial of their Political and Religious Implications », dans Wael Hallaq et Donald Little (éd.), Islamic Studies Presented to Charles J. Adams (Leiden, Brill : 1991), 117-132.
} 
déterminisme ni liberté absolue, mais quelque chose entre les deux » (lā ğabr wa lā tafwị̣̂ wa lākin amr bayna amrayn $)^{15}$. Mīr Dāmād, dans son Épître des éveils, s'efforce de donner un sens conceptuel précis à cette formule suggestive mais vague. Voici un extrait de sa longue introduction :

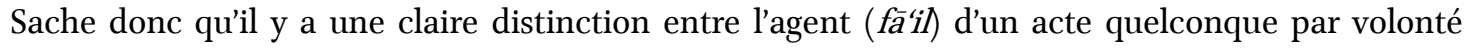
(irāda) et choix (ihtiyār) et l'Instaurateur accompli (al-ğăíil al-tāmm) nécessitant [cet acte] par sa volonté et son choix. [L'Instaurateur] est le principe d'effusion de l'existence [de l'acte] (al-mufị̀ li-wuğūùdihì) comme de celle de ses causes, moyens, conditions et attendus (muntazarāt) dans l'absolu. Quant au sujet d'initiative (al-mubāšir) dont le choix est le dernier terme par lequel s'accomplit la cause de son acte, il est bien l'agent de cet acte par choix, que ce soit au sens linguistique, courant ou technique, pour le commun comme pour l'élite, mais il n'est pas l'Instaurateur accompli nécessitant [cet acte] par volonté et choix, à moins qu'il n'effuse lui-même son existence, avec les causes et les moyens dont il a besoin, de manière irrévocable.

Si tu as compris cela, il t'apparaîtra que l'homme, en tant qu'il est le sujet d'initiative de son acte et de son choix, est le dernier attendu de l'acte, la dernière partie de sa cause complète, et qu'il doit être l'agent libre de ses actes et de ses œuvres. Mais en tant qu'il n'est pas celui qui effuse l'existence de l'acte, de ses causes et de ses moyens (...), il n'est pas l'Instaurateur accompli, celui qui existentie et nécessite ses actes par pure nécessité. Cet Instaurateur accompli, qui existentie et nécessite tous les atomes du système de l'être par volonté et choix, n'est nul autre que le Souverain suffisant et véritable, effusant absolument tous les mondes de l'existence, du plus infime au plus immense. Ceci n'est nullement contredit par la médiation des causes, des moyens, des conditions et des relations, qui effusent tous de Sa puissance d'effuser véritable et absolue (...).

Cette explication est propre à soulever le voile du mystère du secret contenu dans la parole de nos maîtres purs et infaillibles (...) : «Ni prédétermination ni liberté absolue mais quelque chose entre les deux ». Là-dessus, tu as entendu l'un de nos associés et prédécesseurs parmi les sages enracinés [dans la science] (min al-ḥukamā' al-rāsih̆inn) [Avicenne] dire : «L'homme est contraint sous la forme d'un être libre » (al-insān muḍtarr fis șūra muhtăr); et parmi eux, certains renverser le propos et dire : «L'homme est libre sous la forme d'un être contraint $»^{16}$.

La distinction conceptuelle entre l'homme comme agent ou sujet d'initiative de ses actes, l'homme dont la volonté et le choix sont la cause dernière de ses actes, et Dieu comme «Instaurateur » de tous les actes, principe d'effusion de toute existence, Cause première ou Cause des causes, repose sur une conception

\footnotetext{
${ }^{15}$ Al-'Allāma al-Ṭabarsī, al-Iḥtiğāğ, éd. Ibrāhīm Bahādarī et Muḥammad Hādībeh, 2 vol. (Qom : Uswa, 1413/1992-3), I, 310. Le tafwịd, que nous traduisons par « liberté absolue », signifie littéralement la « délégation de pouvoir ».

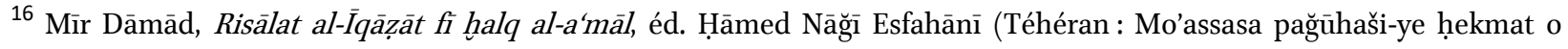
falsafeh, 1391 h.s./2012-3), 4-6. Pour la citation d'Ibn Sīnā : al-Talìqāt, éd. 'Abd al-Raḥmān Badawī (Beyrouth: Maktabat ali'lām al-islāmī, 1404/1983-4), 51, ou éd. Husayn Mūsaviyān (Téhéran : Mo'assasa pağūhaši-ye hekmat o falsafeh, 1391 h.s.(2012-3), 124.
} 
métaphysique néoplatonicienne dans laquelle Dieu, en Lui-même dans l'éternité pure ou le Non-temps (sarmad), émane ou effuse (ar. fayḍ équivalent du gr. proôdos) le monde intelligible dans une durée éternelle ou Méta-temps (dahr) qui enveloppe elle-même la génération naturelle des êtres dans le temps (zamān) ${ }^{17}$. L'enchaînement causal des événements naturels, dans sa totalité, est l'effet temporel de la puissance d'instauration (ğăailiyya) ou d'effusion (fayyādiyya) éternelle de Dieu; et le choix de l'homme est le dernier maillon de l'enchaînement causal aboutissant à son acte. Contre la théologie ash'arite voulant qu'il n'y ait d'agent ( $f_{\bar{a}}$ î $)$ que Dieu, Mīr Dāmād soutient que l'homme est bien l'agent de ses actes, mais en un sens tout différent de celui de l'agentivité divine. L'homme, en tant qu'être possible par essence, est un agent libre conditionné et ne l'est qu'en vertu de la liberté inconditionnée de Dieu, l'Être nécessaire par soi, qui confère à toute chose son existence et sa nécessité. La liberté de Dieu est une liberté nécessitante ; elle est la nécessité même de son Essence. La liberté de l'homme est une liberté nécessitée, inscrite dans la trame même du déterminisme naturel. Ici, notre auteur s'efforce non seulement de concilier le libre arbitre humain et la Volonté divine toute-puissante, mais aussi la Volonté comme attribut essentiel de Dieu, conformément à la théologie commune de l'islam, et le paradigme du mode d'action divine par effusion ou émanation (fayḍ), immanente et non intentionnelle. Ceci n'est possible qu'en identifiant liberté et nécessité d'une manière qui rappelle les conceptions de Spinoza, contemporain de notre auteur ${ }^{18}$. De même chez Mīr Dāmād : si la Volonté divine agit sur le mode d'un influx impersonnel, c'est qu'elle est l'expression nécessaire de l'Essence divine ; et si la liberté humaine participe au déterminisme naturel, c'est qu'elle est l'expression même de la nature de l'homme non entravée.

Il semble que la formule imâmite «Ni déterminisme ni liberté absolue, mais quelque chose entre les deux » ne trouve sens que dans le cadre d'une métaphysique qu'il revient au philosophe de formuler. Le philosophe est l'exégète de l'imâm, lui-même herméneute de la Révélation coranique selon la doctrine originelle du shi'isme ${ }^{19}$. Mīr Dāmād s'associe d'ailleurs au šayh̆ ra’īs Ibn Sīnā (Avicenne, m. 428/1037) parmi les « sages enracinés [dans la science] », faisant allusion au verset Cor. 3:7 dans sa lecture shicite - « Nul ne connaît l'interprétation [du Livre] sinon Dieu et les hommes enracinés dans la science» - qui, selon l'exégèse traditionnelle, désigne par «les hommes enracinés dans la science» les seuls imâms. Toutefois, au lieu d'une explication logique de la formule, c'est un double paradoxe qui est proposé : «l'homme est contraint sous la forme d'un être libre», formule d'Ibn Sīnā faisant de la liberté une apparence exotérique (zāhir) et du

\footnotetext{
${ }^{17}$ Sur cette tripartition développée par Mīr Dāmād à partir d'Avicenne, voir Toshihiko Izutsu, « Mîr Dâmâd and his Metaphysics », dans Mīr Dāmād, Kitāb al-Qabasāt, éd. Mahdī Muḥaqqiq (Téhéran : Mo'assasa entešārāt o čāp-e dānašgāhe Tehrān, 1977-2016), introduction, 1-15 ; Fazlur Rahman, « Mīr Dāmād's Concept of ḥudūth dahrī : A Contribution to the Study of God-World Relationship Theories in Safavid Iran », Journal of Near Eastern Studies 39, 2 (1980) : 139-151; Sajjad H. Rizvi, « Between Time and Eternity: Mīr Dāmād on God's Creative agency », Journal of Islamic Studies 17:2 (2006): 158-176 ; Mathieu Terrier, «De l'éternité ou de la nouveauté du monde: parcours d'un problème philosophique d'Athènes à Ispahan », Journal Asiatique 299.1 (2011) : 369-421. Cette distinction se trouve d'abord chez Ibn Sīnā, Talīqāt, 43, 141-142 B ; 98-99, 421-423 M.

18 «Est dite libre, la chose qui existe par la seule nécessité de sa nature et se détermine par soi seule à agir » (Spinoza, Éthique, trad. Bernard Pautrat (Paris : Le Seuil, 2010), partie I, définition VII, 17) ; « Dieu agit par les seules lois de sa nature, et contraint par personne » (Ibid., partie I, proposition XVII, 47).

${ }^{19}$ Voir Mohammad Ali Amir-Moezzi, Le Coran silencieux et le Coran parlant. Sources scripturaires de l'islam entre histoire et ferveur (Paris : CNRS éditions, 2011).
} 
déterminisme une réalité cachée ou ésotérique (bāțin); et «l'homme est libre sous la forme d'un être contraint », où le déterminisme devient manifeste et la liberté cachée. En somme, il est à la fois vrai de dire, avec Spinoza, que l'homme est déterminé quand bien même il se croit libre, et avec Sartre, que l'homme est libre même quand il se croit déterminéé .

Cette conception de la liberté humaine pose toutefois le problème de la théodicée au niveau de la Justice divine rétributive :

La question subsiste du mérite des récompenses et des châtiments évoqués par la Promesse et la Menace dans les saintes Révélations et les paroles prophétiques. L'action du serviteur étant subordonnée à sa volonté, si sa volonté de l'acte, sa volonté de la volonté de l'acte, sa volonté de la volonté de la volonté, et ainsi de suite, se produisent nécessairement non pas du fait du serviteur lui-même, mais en vertu d'un autre principe, d'où lui vient le mérite de la récompense et du châtiment?

La théodicée ne doit pas seulement justifier le mal moral, commis ou subi par l'homme dans sa vie terrestre, mais aussi le mal eschatologique, rendu par Dieu dans la vie dernière - un mal dont l'existence ne fait aucun doute, annoncé qu'il est par la Révélation, et qu'il faut justifier par la Bonté même de Dieu. La réponse de notre philosophe conjugue encore les données de la révélation et celles de la philosophie, ces dernières confirmant et explicitant les premières :

Comprends donc: de même que l'action du serviteur, sa volonté et son choix, relèvent du Décret seigneurial et de la Détermination divine, comme le dit le Saint Coran : «Bien que vous ne vouliez que si Dieu veut» (Cor. 76:30) et «Ne dis pas non plus d'une chose que tu vas la faire demain sans ajouter: «Pourvu que Dieu le veuille »» (Cor. 18:23-24), de même la récompense et le châtiment relèvent du Décret et de la Détermination, comme l'a dit notre associé et prédécesseur à la tête de la philosophie islamique

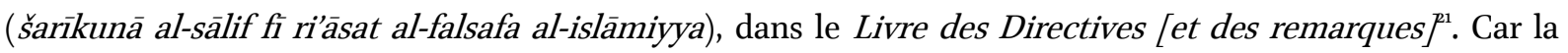
nécessitation de la récompense et de la punition fait partie des concomitants (lawāzim) des bonnes et des mauvaises actions, inégaux dans leurs réalités véritables, différents dans leurs degrés de beauté et de laideur essentiels (...). La différence de ces degrés de beauté et de laideur est le principe de la nécessaire différence des récompenses et des châtiments divins. Cela ne revient qu'au sujet d'initiative car il est le substrat récepteur - non à Celui qui effuse et existentie ${ }^{22}$.

\footnotetext{
${ }^{20}$ Spinoza, Éthique, partie III, proposition II, scolie, 216-223; Jean-Paul Sartre, L'existentialisme est un humanisme (Paris : Nagel, 1946).

${ }^{21}$ Ibn Sīnā, Al-Išārāt wa-l-tanbīhāt, éd. Muğtabā Zārīī (Qum: Bustān-i kitāb, 1387 h.s./20o8-9), 337 ; Avicenne, Livre des directives et des remarques, trad. Amélie-Marie Goichon (Paris : Vrin, 1999, 1' ère éd. 1951), 463 ; Nașīr al-Dīn al-Ṭūsī, Šarh alIšārāt wa-l-tanbīhāt, éd. s.n., 3 vol. (Qum : Našr al-balāgaa, 1375 h.s./1996-7), vol. 3, 328-329. Mīr Dāmād fait ici allusion au surnom honorifique d'Avicenne, «le chef de file [des philosophes]» (al-šayh̆ al-ra'šs), dont il s'estime être le digne successeur.

${ }^{22}$ Cette citation et la précédente : Mīr Dāmād, İqāzāt, 12.
} 
Si la rétribution des bonnes et des mauvaises actions est donc, comme ces actions elles-mêmes, le fait du Décret et de la Détermination (al-qaḍā' wa l-qadar), c'est au sens où le mérite de la récompense ou de la punition est un concomitant nécessaire de la quiddité des actions. Dès lors, la volonté divine n'en est plus essentiellement la cause :

Sache ensuite que les maux et les souffrances advenant dans l'être, dans cette vie comme dans la vie dernière, ne sont attribuables à la Volonté du Seigneur et à l'Effusion du Glorifié que par accident, en tant qu'ils sont les concomitants des biens nombreux qui, selon la loi de l'Effusion véritable et de la Donation absolue (al-fayyādiyya al-ḥaqqa wa-l-wahhābiyya al-muṭlaqa), dépendent naturellement de Sa Volonté par essence. De même, (...) les concomitants de la quiddité (lawāzim al-māhiyya) ne peuvent être attribués par essence qu'à la quiddité ; et ne sont attribués que par accident à l'Instaurateur de la quidditée ${ }^{23}$.

L'argument est double : 1) Les maux de la vie terrestre comme ceux de la vie dernière, ici pensées en complète solidarité, ne sont pas voulus par Dieu pour eux-mêmes, mais sont les concomitants de biens innombrables voulus par essence, c'est-à-dire découlant nécessairement de l'Essence divine. Ceci rejoint l'argument leibnizien du minimum de mal nécessaire pour un maximum de bien possible ${ }^{24}$. Ainsi, les méfaits des pécheurs ici-bas et leurs supplices dans l'au-delà ne sont attribuables que par accident à la Volonté divine, quand les bienfaits supérieurs dont ils sont les concomitants lui sont attribuables par essence. 2) Les concomitants d'une quiddité ne sont imputables par essence qu'à cette quiddité et non à l'Instaurateur de toute quiddité qu'est Dieu. Les récompenses et les punitions reviennent donc essentiellement aux sujets de la vie dernière, tout comme leurs actes leur reviennent essentiellement durant leur vie terrestre. Se dégage ici l'idée, fort peu orthodoxe, d'une Justice immanente se produisant d'elle-même sans intervention d'un Juge transcendant - nous y reviendrons.

Pour justifier la première partie de l'argument, le philosophe s'appuie sur la distinction, classique dans la théodicée avicennienne, du point de vue universel et du point de vue particulier, en s'appuyant sur l'analogie entre le monde comme «macranthrope » (insān kabìr) et l'homme comme « microcosme » ('ālam șag̀ìr :

Les maux voulus [par Dieu] - par accident et non par essence - dans les deux vies n'ont de mauvaiseté que du point de vue de certaines parties de l'univers, prises dans leur particularité, en petit nombre comparé à toutes les parties. Du point de vue du système total dans son individualité synthétique (bi-šahșiyyatihi al-ğumliyya), ou du point de vue de ces parties en tant que parties de l'individu synthétique et du système universel parfait, il n'y a absolument aucun mal et rien de mauvais ${ }^{25}$.

\footnotetext{
${ }^{23}$ Mīr Dāmād, İqāzăt, 13.

${ }^{24}$ Leibniz, Essais de théodicée (Paris : Garnier-Flammarion, 1969), 108-109.

${ }^{25}$ Mīr Dāmād, İqāzāt, 13.
} 
Mīr Dāmād précise une implication importante de sa distinction entre le Décret et la Détermination, correspondant à deux niveaux du gouvernement divin : «Les maux advenant dans l'existence n'entrent par accident que dans le Décret, pas dans la Détermination. Car ce que le Décret exige par essence [c'est-à-dire le bien] ou par accident [c'est-à-dire le mal], rassemblé dans le système synthétique et la direction universelle, la Détermination l'expose par essence et le détaille en menues parcelles à travers la multiplicité, l'échelonnement, l'antériorité et la postériorité $»^{26}$. L'on croit comprendre que le mal, exigé accidentellement par le Décret, devient essentiel dans la Détermination, mais sans nuire en rien à la perfection du système. Ainsi le mal peut-il être à la fois inessentiel au niveau de la Volonté divine et bien réel dans l'existence naturelle et historique de l'homme.

Dans le premier chapitre («éveil») de sa Risālat al-Īqāzăt, Mīr Dāmād identifie la racine des maux à l'imperfection des matières-substrats et des quiddités appartenant au monde de la Nature ou de la Détermination :

Les biens et les perfections du système de l'être (...) procèdent tous par essence de la Volonté vraie et nécessaire de Dieu (...), même si leur effusion, procédant de Sa Libéralité immense, est à la mesure des dispositions des matières et des mérites propres des quiddités. Les maux, les souffrances, les imperfections et les péchés proviennent en eux-mêmes des mauvaises dispositions, des dignités défectueuses, des heurts advenant entre les êtres matériels, des entrechocs entre les habitants du monde des ténèbres. [Ces maux] ne viennent ni d'une avarice du principe d'effusion (...), ni d'un manque de puissance ou d'un défaut dans l'Effusion elle-même, le Très-Haut est bien au-dessus de cela. De là Sa noble parole dans la sage révélation : «Tout bien qui t'arrive vient de Dieu, tout mal qui t'arrive vient de toi » (Cor. 4:79) ${ }^{27}$.

De ce qui précède, il ressort que cette imperfection inégale des matières et des quiddités est la condition de la perfection du système total de l'existence. On remarque qu'ici encore sont justifiés ensemble les maux physiques (les souffrances), métaphysiques (les imperfections) et moraux (les péchés).

Mīr Dāmād cite ensuite un argument-clé de la théodicée avicennienne d'après Bahmanyār b. alMarzubān (m. 458/1067), commentateur d'Ibn Sīnā : « Tout ce dont l'existence a atteint sa perfection ultime et ne contient rien en lui qui soit en puissance ne se voit attacher aucun mal; le mal est inexistence ou imperfection d'une existence $»^{28}$. Mīr Dāmād, ici, entend moins nier la réalité du mal moral qu'y voir la preuve de la Bonté absolue de la création. Ce qu'exprime une autre citation de Bahmanyār : « Il fallait que les choses auxquelles le mal est attribué existent dans ce système qui est tout entier bien, sagesse et ordre. Il n'a pas été

\footnotetext{
${ }^{26}$ Mīr Dāmād, İqāzāt, 14.

${ }^{27}$ Mīr Dāmād, İqāzāt, 15 .

${ }^{28}$ Mīr Dāmād, İqāzāt, 24; Bahmanyār b. Mazarbān, Kitāb al-Taḥṣil, éd. Murtaḍā Muțṭaharī (Téhéran : Entešārāt-e dānašgāh-e Tehrān, 1375 h.s./1996-7), 657-658.
} 
dans la Sagesse [divine] de ne pas créer cette création à laquelle est attaché quelque mal ${ }^{29}$. Ceci rappelle encore Leibniz affirmant que «Dieu n'aurait pas été parfaitement bon, parfaitement sage, s'il avait exclu [le vice] $\gg^{3^{\circ}}$. Mais en ayant à l'esprit le premier texte étudié ici, l'introduction du Šări al-nağăt, on peut se demander si cette sagesse est accessible à la raison humaine.

Dans le troisième « éveil » de son épître, Mīr Dāmād revient sur le problème du libre arbitre ou de la prédétermination pour résoudre une question hérésiologique, concernant donc le mal moral non plus dans les actions mais dans les croyances. Il s'agit d'identifier les hommes visés par le Prophète dans ce hadīt : « Ceux qui professent le qadar [ou sa négation] (al-qadariyya) sont les mazdéens (mağūs) de cette communauté. Ils sont maudits par les langues de soixante-dix prophètes $»^{3^{1}}$. Les ash'arites prétendent que ce sont les partisans de la justice et de l'unicité divine (așhāab al-'adl wa-l-tawḥìd), c'est-à-dire les mu'tazilites et les shi'ites, parce qu'ils rejettent la Détermination (qadar) pour affirmer le libre arbitre de l'homme ; ainsi admettent-ils pour certaines actions un autre principe que l'Être nécessaire par soi, tout comme les mazdéens affirmaient l'existence de deux principes, l'un des bonnes actions, Yazdān, l'autre des mauvaises, Ahriman ${ }^{32}$. Mīr Dāmād réfute et retourne l'accusation contre les ash'arites, représentants du sunnisme sur le plan théologique :

La divergence et l'hostilité portent sur la question de savoir si le principe prochain de l'action de l'homme, auquel est attribuée la conséquence comme à son origine, est la capacité et la volonté [de l'homme lui-même] ou la Puissance nécessaire du Seigneur et la Volonté véritable de Dieu. L'accusation de sophisme (tašbīh) ne concerne pas la thèse de la dualité du principe (al-qawl bi-tatniyat al-mabdā), mais se fonde sur ce que les mazdéens dépossèdent l'homme de toute intervention sur ses actes en attribuant ses bonnes actions à Yazdān et ses mauvaises à Ahriman. Ainsi font les partisans du déterminisme et de l'acquisition (al-muğabbara wa-l-kasbiyya) [les ash'arites], à ceci près qu'ils attribuent tout, depuis l'origine, à Dieu l'Unique et l'Impérieux ${ }^{33}$.

Mīr Dāmād revient alors à la formule imâmite : «Ni déterminisme ni liberté absolue, mais quelque chose entre les deux ». Après en avoir cité le commentaire par Nașīr al-Dīn al-Ṭūsī (m. 672/1274), à qui l'on doit d'avoir introduit la philosophie avicennienne en milieu shicite imâmite ${ }^{34}$, il la rapproche à nouveau de la formule d'Ibn Sīnā ainsi introduite et augmentée : « Les principes prochains des actions du serviteur [de Dieu] sont fondés sur sa capacité et son choix ; les principes lointains de ses actions sont fondés sur son impuissance

\footnotetext{
${ }^{29}$ Mīr Dāmād, İqāzā̄t, 25 ; Bahmanyār b. Mazarbān, Taḥ̣̂̄l, 661.

${ }^{30}$ Leibniz, Essais, 181.

${ }^{31}$ Mīr Dāmād, İqāzāt, 31. Version différente dans al-Kulaynī, Ușūl al-Kāfi, Kitāb al-Tawḥìd, bāb al-huayr wa l-šarr, 88, ḥ. 2 ; Ibn Bābūya (Šayh̆ Ṣadūq), Kitāb al-Tawhīd, éd. s.n. (s.l. : Dār al-aḍā̄', 1430/2009), 250, h. 29.

${ }^{32}$ Mīr Dāmād, $\bar{I} q \bar{a} z \bar{a} t, 32$.

${ }^{33}$ Mīr Dāmād, İqāzāt, 33 .

${ }^{34}$ Mīr Dāmād, İqāzāt, 35-37 ; Nașīr al-Dīn al-Ṭūsī, Talhīṣ al-Muhaș̣̣al, éd. 'Alī Nūrānī (Téhéran : Mo'assasa muṭāla'āt-e eslāmī-ye ğāme‘at-e Māk Gīl va ğāme‘at-e Tehrān, 1359 h.s./1980), 334.
} 
et sa contrainte. L'homme est contraint sous la forme d'un être libre, comme le calame dans la main de l'écrivain ou le pieu dans la fissure du mur ${ }^{35}$.

Dans le quatrième «éveil » de son épître, Mīr Dāmād développe cette position par des traditions imâmites extraites des recueils canoniques d'al-Kulaynī (m. 328/939-4O ou 329/940-41) et d'Ibn Bābūya (m. $381 / 991)$. De ces traditions appartenant à la période originelle, ésotérique et non rationnelle du shi'isme ${ }^{36}$, se dégage une véritable aporie philosophique. Des cinquième et sixième imâms, Muhammad al-Bāqir (m. 115/732 ou 119/737) et Ğa'far al-Ṣādiq : « Dieu est trop clément à l'égard de Ses créatures pour les contraindre aux crimes et les punir ensuite pour cela; Dieu est trop puissant pour vouloir quelque chose et que cela ne soit pas. » On leur demanda : «Y a-t-il une station entre le déterminisme et la [négation de] la Détermination (bayna l-ğabr wa-l-qadar) ?» Ils répondirent : «Cette station est plus vaste que la distance entre le ciel et la terre ${ }^{37}$. Selon une autre tradition, la définition de cette position intermédiaire relève d'un enseignement secret, voire interdit : alors qu'un disciple insistait pour connaitre cette station, le sixième imâm finit par déclarer: «Si je te répondais à ce sujet, tu deviendrais impie » (law ağabtuka fihi la-kafirta $)^{38}$. Mīr Dāmād rapporte aussi, du sixième imâm, le hadịt de la création du bien et du mal évoqué dans notre introduction :

Parmi ce que Dieu révéla à Moïse et fit descendre pour lui dans la Torah, ceci : «C'est Moi qui suis Dieu, il n'est de dieu que Moi ! J'ai créé les créatures, puis J'ai créé le bien. J'en ai versé sur les mains de ceux que J'aime, heureux soient ceux sur les mains desquels J'en ai versé ! C'est Moi qui suis Dieu, il n'est de dieu que Moi ! J'ai créé les créatures, puis J'ai créé le mal. J'en ai versé sur les mains de ceux que Je veux, malheur à ceux sur les mains desquels J'en ai versé ${ }^{39}$ !

Les traditions suivantes approfondissent le paradoxe avec une distinction, que l'on peut dire préconceptuelle, entre la volonté de Dieu (maš̃̄a sixième imâm encore : «Dieu a voulu que je sois capable de faire ce qu'Il n'a pas voulu que je fasse »; «Dieu a voulu et résolu (šấa wa arāda) mais n’a pas aimé ni agréé (lam yuḥibb wa lam yarḍa). Il a voulu que rien ne soit dans Son règne sinon par Sa science et a résolu de même ; mais Il n'a pas aimé que l'on dise de Lui qu'Il est « le troisième de trois» (Cor. $5: 73$ ) et n'a pas agréé l'impiété de Ses serviteur $»^{40}$; «Dieu ordonna et ne voulut point, voulut et n'ordonna point. Il ordonna à Iblīs de se prosterner devant Adam et voulut qu'il ne se prosterne pas ; si Dieu l'avait voulu, Iblīs se serait prosterné. Dieu interdit à Adam de manger [du fruit de] l'arbre et voulut qu'il en mange ; si Dieu ne l'avait pas voulu, Adam n'en aurait pas mangé $»^{41}$. De telles traditions, à l'évidence,

\footnotetext{
${ }^{35}$ Mīr Dāmād, İqāzăt, 38.

${ }^{36}$ Sur cette caractérisation, voir Amir-Moezzi, Guide divin, introduction, 13-71.

${ }^{37}$ Mīr Dāmād, İqāzāt, 43-44 ; al-Kulaynī, Ușūl, K. al-Tawḥìd, bāb al-ğabr wa-l-qadar wa-l-amr bayna l-amrayn, 9o, h. 9 ; Ibn Bābūya, Tawhīi, 236, h. 3 .

${ }^{38}$ Mīr Dāmād, İqāzāt, 51 ; Ibn Bābūya, Tawhīe, 238, ḥ. 11.

${ }^{39}$ Mīr Dāmād, İqāzāt, 47-48, dans trois versions légèrement différentes ; voir références de la n. 4.

${ }^{40}$ Mīr Dāmād, İqāzāt, 63 ; al-Kulaynī, Ușūl, K. al-Tawḥìd, bāb al-maš̌̀’a wa-l-irāda, 86-87, ḥ. 5 ; Ibn Bābūya, Tawḥìd, 224-225, h. 9 .

${ }^{41}$ Mīr Dāmād, İqāzātt, 72-73 ; al-Kulaynī, Uṣūl, K. al-Tawḥīd, bāb al-mašrì wa-l-irāda, 86, ḥ. 3.
} 
s'accordent difficilement avec la conception philosophique, d'origine néoplatonicienne, d'une création et d'une justice divine par émanation. Mīr Dāmād s'abstient d'affronter ce problème herméneutique. Ce qu'il lui importe de montrer par ces traditions, c'est que la volonté libre de l'homme, même quand elle déplait à Dieu et s'oppose à Son ordre, est dans son essence comme dans son acte un effet de la Volonté absolument libre de Dieu.

C'est ce qu'expriment encore deux hadīțs qudsīs transmis par les imâms. Du quatrième, 'Alī Zayn al‘Ābidīn (m. ca 95/714) : «Dieu dit : « Ô fils d'Adam! Par Ma volonté, tu veux ce que tu veux; par Ma capacité, Mes lois te sont parvenues ; par Ma grâce, tu es capable de Me désobéir. Je t'ai instauré entendant, clairvoyant et puissant. Tout bien qui t'arrive vient de Dieu, tout mal qui t'arrive vient de toi ${ }^{42}{ }^{2}$. Et du premier, 'Alī b. Abī Ṭālib : «Dieu Tout-Puissant révéla au prophète David : «Tu veux, Je veux, et rien ne sera autre que ce que Je veux. Si tu te soumets à ce que Je veux, Je te donnerai ce que tu veux. Si tu ne te soumets pas à ce que Je veux, Je t'épuiserai dans ce que tu veux, et rien ne sera autre que ce que Je veux ${ }^{43} » »$.

Cette conception paradoxale est illustrée par un dernier habar se référant à un contexte historique précis, après la bataille de Șiffin en 37/657, soldée par une défaite politique du calife 'Alī contre l'anti-calife Mu'āwiya, futur fondateur de la dynastie omeyyade. Un vieil homme de l'armée de 'Alī vient voir celui-ci à Kūfa et lui demande si leur marche défaite contre les hommes de Mu'āwiya était le fait du Décret et de la Détermination divines. L'imâm répond qu'ils n'ont effectué aucun mouvement sans que ce soit par le Décret et la Détermination. L'homme lui demande alors si Dieu est responsable de leur souffrance. L'imâm répond qu'ils n’ont jamais été ni contraints ni forcés. L'homme s'étonne : comment n'étaient-ils pas contraints et forcés si tous leurs mouvements dépendaient du Décret et de la Détermination ? L'imâm répond :

Penses-tu qu'il s'agisse d'un Décret inévitable et d'une Détermination nécessaire ? S'il en était ainsi, la récompense et le châtiment, le commandement et l'interdiction, [la louange] et le blâme seraient invalidés, la Promesse et la Menace (al-wa'd wa-l-wa'̂̃d) perdraient tout leur sens, il n’y aurait pas de blâme pour la mauvaise action ni de louange pour la belle action, mais le bel-agissant serait plus digne de blâme que le criminel et le criminel plus digne d'éloge que le bel-agissant ! C'est là le discours des idolâtres, des ennemis du Miséricordieux, des partisans du Satan, des fanatiques de la Détermination (qadariyya) et des mazdéens de cette communautét ${ }^{44}$

La position shi'ite rejoint ici celle des mu'tazilites : le libre arbitre humain est à la fois une condition et une exigence de la Justice divine correctrice ou rétributrice. Mais le contexte de ce habarmontre que le problème de la théodicée se posa d'abord, pour les shi'ites, dans une expérience historique de la défaite et de la souffrance. Ceci nous conduit, chez Mīr Dāmād lui-même, des spéculations sur le mal métaphysique et moral, à une réflexion sur la « vallée des larmes » de l'histoire shicite.

\footnotetext{
${ }^{42}$ Mīr Dāmād, İqāzāt, 44-45 ; Ibn Bābūya, Tawhīe, 224, ḥ. 6.

${ }^{43}$ Mīr Dāmād, İqāzāt, 59 ; Ibn Bābūya, Tawḥīd, 223, ḥ. 4.

${ }^{44}$ Mīr Dāmād, İqāzāt, 49-50 ; Ibn Bābūya, Tawḥìd, 248, ḥ. 28.
} 


\section{Du mal historique au mal métaphysique?}

Mīr Dāmād traite de la dimension historique du Mal dans son Nibrās al-ḍiyā' wa taswā' al-sawā' fì šarh bāb al-badā' wa ițbāt jadwā al-du'ầ' (Le flambeau de la clarté et la balance de l'équité sur le chapitre du badā' et l'attestation de l'utilité de la prière votive), un autre traité de théologie dialectique, composé en arabe entre 1025/1616 et 1034/1623, qui semble s'adresser, théoriquement du moins, à des homologues sunnites ${ }^{45}$. Il traite essentiellement du badấ, l'une des notions les plus complexes et controversées de la théologie shi'ite imâmite ${ }^{46}$. Son argumentation relève successivement des domaines de la théologie, de l'historiographie, de la métaphysique et de la «science des lettres » ( $i l m$ al-ḥurūff), illustrant la polyvalence de ce penseur.

Le terme arabe badā' est le nom d'action du verbe badālyabdū signifiant «apparaître à », «se manifester». Dans le langage technique de la théologie imâmite, il signifie un changement apparent de la Volonté divine, quand se produit un événement contraire à l'annonce d'un prophète ou d'un imâm ${ }^{47}$. L'idée que Dieu puisse changer sa décision en fonction des circonstances fut d'abord défendue par les Kaysanides, des shicites révoltés partisans de Muhtār b. Abī 'Ubayd al-Taqaaì (m. 67/687) ; après une défaite subie en 67/686-7, leur chef aurait allégué qu'un nouveau décret était apparu à Dieu (badā lahu) en invoquant le verset Cor. 13 : 39: «Dieu efface ou confirme ce qu'Il veut». Après la disparition des Kaysanides, le badā’ fut intégré dans l'enseignement des cinquième et sixième imâms ${ }^{48}$. Un hadịt attribué à tous deux affirme : « Dieu n'a jamais été adoré ( 'ubida) [ou exalté ( 'uzzima)] comme Il l'a été par [la croyance dans] le badā"49 ». Cette notion est rejetée par les autres courants shicites, en particulier les ismaéliens, et les théologiens sunnites la considèrent comme hérétique.

Dans son introduction, Mīr Dāmād fait droit à la critique acerbe de Faḩr al-Dīn al-Rāzī, qu'il appelle « le guide des sceptiques » (imām al-mutašakkikīn), lequel voyait dans cette notion un expédient utilisé par les « imâms des contestataires»(al-rāfị̣a), c'est-à-dire les shi'ites ${ }^{50}$, pour justifier leurs échecs et leurs

\footnotetext{
45 Mīr Dāmād, Nibrās al-ḍiyā’ wa taswā' al-sawā’ fi šarḥ bāb al-badā’ wa ițbāt ğadwā l-du'ā', éd. Ḥāmid Nāğì Isfahānī (Téhéran : Mīrāt-e maktūb, 1374 h.s./1995). Sur cet ouvrage, voir Mathieu Terrier, « The Wisdom of God and the Tragedy of History: the Concept of Appearance ( badā) in Mīr Dāmād's Lantern of Brightness », dans Saiyhad Nizamuddin Ahmad et Sajjad Rizvi (éd.), Philosophy and the Intellectual Life in Shīah Islam (Bloomsbury: The Shī'ah Institute Press, 2017), 94-134. Sur cette question et l'influence de cet ouvrage chez Mullā Șadrā, voir aussi M. Terrier, «De l'ésotérisme shi'ite à la philosophie shi'ite. Mullā Șadrā, Mīr Dāmād et la question du badā’», dans Mohammad Ali Amir-Moezzi (dir.), Raison et quête de la sagesse. Hommage à Christian Jambet (Turnhout : Brepols, 2021), 507-55०.

${ }^{46} \mathrm{Il}$ semble que la dernière partie du traité, portant sur la prière votive, soit perdue.

${ }^{47}$ Voir Mohammad Ali Amir-Moezzi, «Badā’ », Encyclopaedia of Islam, 3 éd., éd. Kate Fleet et alii, accessible en ligne : http://dx.doi.org/10.1163/1573-3912 ei3 COM 25083, consulté le 22 octobre 2018.

${ }^{48}$ Wilferd Madelung, «Badā’ », Encyclopaedia Iranica, éd. Ehsan Yarshater, vol. III, Fasc. 4 (New York, 1989), 354-355, accessible en ligne: http://www.iranicaonline.org/articles/bada-theological-term, consulté le 22 octobre 2018 ; 'Abd alQāhir al-Bag̉dādī, al-Farq bayn al-firaq wa bayān al-firqa al-nāğiya minhum, éd. s.n. (Beyrouth : Dār al-afaq, 1408/1987), 38, 5 .

${ }^{49}$ Al-Kulaynī, Ușūl, K. al-Tawḥìd, bāb al-badā', 84, ḥ. 1-2.

${ }^{50}$ Sur ce terme, voir Etan Kohlberg, « The Term Rāfida in Imami Shì`ī Usage », Journal of the American Oriental Society, 99 (1979) : 677-679, repris dans Etan Kohlberg, Belief and Law in Imāmī Shīism (Aldershot: Variorum Reprints, 1991, art. IV).
} 
contradictions. «Quand ils disent que l'autorité et la puissance leur reviendront et que les choses n'arrivent pas comme ils l'ont annoncé, ils disent : «Il est apparu à Dieu [quelque chose] dans cette affaire » (badā Allāh ta‘ālā fihhi $)^{51} »$. Les imâms auraient de même employé la notion de «dissimulation pieuse » (taqiyya) pour couvrir a posteriori leurs erreurs.

En bon théologien imâmite, Mīr Dāmād ne rapporte cette critique que pour mieux y répondre. Il réplique que le badā'n'est pas seulement présent dans l'enseignement des imâms, mais aussi attesté dans des ḥadīts du Prophète rapportés par les ouvrages canoniques du sunnisme ${ }^{52}$. Quant à la taqiyya, elle n'a pas seulement pour but l'évitement d'un mal subi (⿳亠丷arar), mais la purification (iḥlāṣ) et la proximité de Dieu $(q u r b a)^{53}$. Ainsi s'explique, pour notre auteur, l'attitude des imâms shicites face au mal historique que fut l'usurpation de leur droit au pouvoir temporel :

Nos purs imâms n'ont jamais dissimulé à personne la manifestation de leur rang et la proclamation de leur dignité. Leur réticence (tatabbuț) à réclamer leur droit et le pouvoir effectif sur leurs sujets, à défendre leur position contre les usurpateurs de leur droit, était due à la faiblesse de leurs partisans et à la perte de leurs soutiens. C'était l'acceptation de l'écrit du Calame divin, la soumission à l'effet de la Détermination, l'application de la recommandation de l'Envoyé de Dieu. Aucun d'entre eux n'a jamais renoncé à éclairer ce qu'il y a d'obscur dans les sciences des réalités essentielles et la connaissance de la Souveraineté divine, à expliciter ce qui a été révélé des jugements relatifs à la religion et des limites posées par Dieu, selon les voies de la révélation littérale (tanzīl) et de l'interprétation ésotérique ( $\operatorname{ta}$ 'wīl), à porter le flambeau de la science et de la sagesse, la lampe de la sainteté et de l'infaillibilité ${ }^{54}$.

Mīr Dāmād fait ici référence à l'attitude passive et quiétiste des imâms : le premier, 'Alī b. Abī Ṭālib, sous les trois premiers califes; le deuxième, al-Ḥasan sous le premier Umayyade Mu'āwiya; et après le troisième, al-Husayn - le seul à avoir combattu et dont le martyre n'est pas évoqué ici -, les huit suivants, sous les Umayyades puis les 'Abbassides. Cette attitude est désignée comme « réticence » (tatabbuț), avec aussi le sens négatif de «tergiversation » et d' « atermoiement »; de nombreuses traditions relatent en effet comment les imâms, devant l'impatience de leurs partisans, n'ont cessé d'ajourner le combat pour rétablir leur droit, jusqu'à le renvoyer finalement à la parousie du Mahdī, le retour du douzième imâm Muḥammad b. al-Ḥasan al'Askarī, occulté depuis 26o/874. Pour Mīr Dāmād, il ne s'agissait aucunement de dissimulation ou d'hésitation sur leur droit, mais d'une acceptation du Décret et de la Détermination, en l'occurrence du badā' par lequel Dieu a ajourné sa décision de leur remettre, à eux les Impeccables (al-mașūmūn), tout le pouvoir après le Prophète, et a laissé leurs adversaires faire ce qu'Il n'aime pas. Encore ce mal historique apparait-il comme un moindre mal, affectant seulement l'aspect extérieur, exotérique de leur mission, tandis que les imâms n'ont renoncé en rien à l'essentiel de leur mission, la connaissance spirituelle ésotérique de Dieu et de la révélation.

\footnotetext{
${ }^{51}$ Mīr Dāmād, Nibrās, 6.

${ }^{52}$ Mīr Dāmād, Nibrās, 7. Il s'agit des Saḥị̣h respectifs de Buhārī et de Muslim, ainsi que des ouvrages de Tirmiḍī et de Malik.

${ }^{53}$ Mīr Dāmād, Nibrās, 10.

${ }^{54}$ Mīr Dāmād, Nibrās, 10.
} 
Dans les pages suivantes, Mīr Dāmād révise l'histoire des débuts de l'islam comme une série de maux subis par les «gens de la Sainte Famille » et de crimes commis par leurs adversaires, contredisant la volonté expresse de Dieu. Pour ce faire, il s'appuie principalement sur des sources sunnites corroborant les thèses shi'ites, ce qui témoigne de l'intention dialectique et polémique de l'épître. Il revient d'abord sur le quiétisme de l'imâm 'Alī qui, après la mort du Prophète, renonça à combattre pour faire valoir son droit à sa succession, malgré sa conviction d'avoir été choisi par Dieu et le Prophète ; attitude dont les sunnites tirent argument pour soutenir qu'il accepta la désignation d'Abū Bakr, de 'Umar puis de 'Uțmān avant lui. Cet épisode est perçu par les shicites et notre auteur comme la source de tout le mal historique :

Il en fut ainsi de la vie du Prince des croyants, 'Alī b. Abī TTālib, à l'époque où remonte toute l'affaire : il ne leva pas le combat sacré ( ̆ğihād) pour son califat mais ne renonça pas à réclamer son droit et à revendiquer sa position. Les voleurs du califat (luṣūṣ al-ḩilāfa), ceux qui s'en emparèrent et s'en revêtirent, lui réclamèrent son allégeance en disant : «Prête nous allégeance, ou nous frapperons ceux qui sont pour toi comme la prunelle de tes yeux !» Il leur dit : «Il revient bien plutôt à vous de me prêter allégeance qu’à moi de vous prêter allégeance.» Il dit aussi : «Nous connaissions notre droit dans cette affaire, mais vous nous avez subjugué par la force.» Il dit aussi : «Je suis le premier à m’accroupir [avant de me dresser] contre les ennemis devant Dieu $! \gg^{55}$.

Après avoir cité de nombreuses attestations de la supériorité morale ( $f a \underline{d} l)$ des imâms sur les califes en place, Mīr Dāmād affirme qu'une « détestation mutuelle » (mubāgagạa) n’a cessé d'opposer, après la mort du Prophète, les «gens de la sainte Famille » aux trois premiers califes et à la «mère des croyants » 'Á'iša ${ }^{56}$. Il rappelle comment Fāțima fut spoliée par Abū Bakr de son droit sur l'oasis de Fadak avant de mourir, six mois seulement après son père ${ }^{57}$, mais sans évoquer l'agression fatale de la fille du Prophète par des hommes de main d'Abū Bakr et de 'Umar, un récit familier des shicites mais absent des sources sunnites; et comment 'Alī enterra Fāṭima de nuit, en secret. Comme l'attestent toutes les sources, ce n'est qu'après cette perte que 'Alī se résigna à prêter allégeance à Abū Bakr. Mīr Dāmād rapporte que l'imâm invita le calife à venir seul chez lui - ce dont 'Umar tente, en vain, de dissuader son complice - et le fit pleurer de repentir en lui rappelant sa proximité avec le Prophète. Alors « [quelque chose] apparut [à 'Alī] pour Abū Bakr» (badā li-Abī Bakr) et il lui prêta

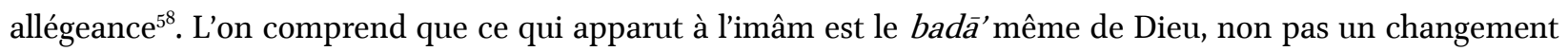
de volonté essentielle sur le plan méta-temporel du Décret (qậāa), la souveraineté de l'imâm étant toujours décrétée par Dieu, mais une suspension de son exécution sur le plan temporel de la Détermination (qadar).

Mīr Dāmād passe ensuite au rapport des traditions imâmites. L'usurpation du califat promis à 'Alī y apparaît déjà prévisible du vivant du Prophète et confusément prévue par celui-ci. Selon l'exégète shicite alṬabarsī (m. 548 /1154), le verset Cor. 17 : 6o : « Nous n'avons fait de la vision que nous t'avons montrée, ainsi que

\footnotetext{
${ }^{55}$ Mīr Dāmād, Nibrās, 11 ; également dans al-Mağlisī, Bị̂̄ār, vol. 19, 313, ḥ. 61.

${ }^{56}$ Mīr Dāmād, Nibrās, 36, se référant aux deux Șaḥị̣ de Buhārī et de Muslim.

${ }^{57}$ Mīr Dāmād, Nibrās, 36-37.

${ }^{58}$ Mīr Dāmād, Nibrās, 37.
} 
de l'arbre maudit, mentionné dans le Coran, qu'une tentation pour les hommes», se réfère à un rêve dans lequel le Prophète vit des hommes grimpant sur la chaire de sa mosquée comme des singes et poussant les gens à l'apostasie, vision après laquelle personne ne l'entendit plus rire de sa vie ; ces hommes sont les Umayyades, désignés aussi par «l'arbre maudit ». Par ce rêve, Dieu avait informé le Prophète que cette engeance maudite s'emparerait de sa position et tuerait sa descendance. Du quatrième imâm est ainsi rapportée cette complainte: «Nous [ "gens de la Sainte Famille»] sommes comme les fils d'Israël à l'égard des gens de Pharaon, lesquels ont égorgé leurs fils et déshonoré leurs femmes. Le meilleur des êtres après le Prophète ['Alī] est maudit sur les chaires des mosquées [par les Umayyades]. Ceux qui nous aiment sont spoliés de leur droit à cause de leur amour pour nous!». Mīr Dāmād conclut que le hadịt relatant le rêve du Prophète atteste scripturairement que « la religion de l'islam, après l'Envoyé de Dieu, n'a tourné autour de son axe que du temps où le Prince des croyants ['Alī] put exercer le califat $»^{59}$.

À l'origine de tous les malheurs de l'islam se trouve ce que l'on peut bien appeler un péché originel, la trahison de la volonté du Prophète et de Dieu lui-même, par Abū Bakr et 'Umar. Mīr Dāmād affirme que la vision des singes grimant sur le minbar ne concerne pas exclusivement les Umayyades, mais remonte d'eux à Mu'āwiya, de Mu'āwiya à 'Uttmān, et de lui aux « deux maîtres des voleurs du califat, chefs des ravisseurs de l'imâmat » (šayhay luṣūṣ al-ȟilāfa wa imāmay surrāq al-imāma), Abū Bakr et 'Umarº . En somme, « il est évident que les actions de ces deux-là, au commencement de toute l'affaire, furent comme les graines, et que tout ce qui s'en est suivi fut comme la récolte ${ }^{61} \gg$.

Ceci est confirmé par une tradition bien connue, tant en milieu sunnite que shicite: Muhamammad, sur son lit de mort, demanda des instruments d'écriture (al-qirțās wa-l-ālāt) afin de rédiger un testament prévenant l'égarement des musulmans, mais dut renoncer à cette dernière volonté devant l'hostilité de 'Umar. Pour les shicites, il est certain que cet écrit devait confirmer la désignation de 'Alī comme le successeur du Prophète. Une parole attribuée à Ibn 'Abbās résume la perception shi'ite de l'événement: «Une calamité absolue (alrazīa kullu l-razīa) nous a privés de l'écrit de l’Envoyé de Dieu » ${ }^{62}$.

Mīr Dāmād ne pouvait conclure ce rappel sans évoquer le meurtre du troisième imâm al-Ḥusayn et des siens à Karbalā' (61/680), événement qui cristallise tout le mal historique du point de vue shi'ite. La responsabilité première en incombe encore à Abū Bakr et 'Umar : «al-Husayn a été tué le jour d'al-Saqīfa » ${ }^{63}$, du nom du lieu de la réunion secrète tenue la nuit suivant la mort du Prophète, en l'absence de 'Alī, pour désigner Abū Bakr comme calife.

Si l'on postule la cohérence du traité, il appert que pour Mīr Dāmād, cette suite d'événements tragiques, déterminant toute l'histoire malheureuse de l'islam, relève entièrement du badā'. Mais comme le philosophe le développe ensuite, le badā' n'implique aucun changement dans la Sagesse, la Science et la

\footnotetext{
${ }^{59}$ Mīr Dāmād, Nibrās, 42-43; Abū 'Alī al-Faḍl b. al-Ḥasan al-Ṭabarsī, Mağma' al-bayān fì tafsīr al-Qur'ān, éd. Hāšim al-Rasūlī al-Maḥallātī, 5 vols. (Beyrouth : Dār Iḥyā' al-turāt al-'arabī, 1379/1339 h.s./196o-1), vol. 3, 424.

${ }^{60}$ Mīr Dāmād, Nibrās, 46.

${ }^{61}$ Mīr Dāmād, Nibrās, 46.

${ }^{62}$ Mīr Dāmād, Nibrās, 49. D’après Al-Šahrastānī, Abū l-Fatḥ Muhammad b. 'Abd al-Karīm, Kitāb al-Milal wa-l-niḥal, éd. Muhammad b. Fatḥallāh Badrān, 2 vols. (Le Caire : Maktabat al-anglūl-miṣrīya, 1366/1947, 1375/1955), vol. 1, 29.

${ }^{63}$ Mīr Dāmād, Nibrās, 5 o.
} 
Volonté essentielles de Dieu ; il n'a lieu que dans le monde sensible et temporel de la Détermination (qadar), autrement nommé la « Tablette de l'effacement et de la confirmation » (lawh al-maḥw wa-l-ițāat), en référence au verset Cor. $13: 39$ : «Dieu efface et confirme ce qu'Il veut et, auprès de Lui, est l'Archétype du Livre (umm alkitāb) »; il n'a pas lieu dans le Décret (qaḍ̄ā), le niveau supérieur, intelligible et méta-temporel de l'Effusion divine, qui est cet Archétype même ${ }^{64}$. Le badā'ne traduit pas en réalité un changement de la Volonté divine, laquelle est éternelle et immuable, mais une suspension méta-temporelle de son exécution temporelle, en vue de son accomplissement total à la Fin des temps ; non pas une impuissance ou une hésitation de Dieu, mais la voie impénétrable de sa Sagesse dans la réalisation de son but final. Un sage moratoire du Décret divin : telle serait en définitive la justification théologique et métaphysique de la tragédie de l'histoire du point de vue shi'ite. La notion de badā'permet ainsi à Mīr Dāmād de rendre raison du mal historique dont le sentiment emplit la conscience shicite et de le justifier par une forme de Providence sans rien lui enlever de son caractère douloureux et scandaleux.

\section{Du mal métaphysique au mal eschatologique}

Si Mīr Dāmād ne revient pas ailleurs sur la question historique, il traite encore longuement du problème du mal dans ses dimensions métaphysique, morale et eschatologique, dans la dernière partie de son Kitāb al-Qabasāt (Le livre des charbons ardents), somme métaphysique datée de 1034/1623 et souvent tenue pour son opus magnum ${ }^{65}$. Son point de départ, emprunté à la Théologie du Pseudo-Aristote (le Plotin arabe), est l'identification du Bien pur avec l'Un dont tout procède et auquel tout retourne. Le Bien est ce que désire toute chose, ce par quoi toute chose accomplit le lot de perfection qui est le sien, ce vers quoi est tournée l'essence de toute chose. Mīr Dāmād développe ici une thèse que nous avons vue résumée dans sa Risālat alİqāzāt:

Le mal n'a pas d'essence mais consiste dans l'inexistence d'une essence ( 'adam $\underline{d a} t)$ ), l'inexistence de la perfection d'une essence ( 'adam kamāl dַāt), ou l'inexistence d'une perfection appartenant à une essence ('adam kamāl mā li-dât). Là où il n'y a ni inexistence d'une essence, ni inexistence d'une perfection appartenant à une essence, l'être doué d'intelligence et d'humanité n'imaginera pas la moindre mauvaiseté (šarriyya). L'existence est tout entière un bien, le mal est tout entier inexistence (al-wuğūd kulluhu hayr wal-šarr kulluhu 'adam). Une chose est dite mauvaise par accident quand son existence a pour concomitant l'inexistence d'une perfection [en une autre chose], non en tant qu'elle est existence en réalité. Plus encore, toute la mauvaiseté [d'une chose] est dans le fait d'être mêlée de puissance, et le bien tout entier est du côté du passage de la puissance à l'acte ${ }^{66}$.

\footnotetext{
${ }^{64}$ Mīr Dāmād, Nibrās, 55-57.

${ }^{65}$ Mīr Dāmād, Qabasāt, 428-441.

${ }^{66}$ Mīr Dāmād, Qabasāt, 428.
} 
La double identification de l'existence au bien et de l'inexistence au mal est adoptée par Mīr Dāmād en véritable axiome de son système. Il ne s'agit pas toutefois d'une inexistence absolue mais d'une puissance pure opposée à l'acte pur. Ceci revient à dire que par définition, le mal ne saurait jamais passer à l'acte. Remarquons que cette perspective métaphysique paraît symétriquement inverse de la perspective historique dans laquelle le mal paraît toujours en acte et la Justice divine en perpétuelle puissance jusqu'à la Fin des temps. Mais une autre conséquence paradoxale de cet axiome est que si Dieu, l'Être nécessaire par essence, est Existence pure, Lumière pure et Bien pur, l'être possible, ontologiquement affecté d'inexistence ou de négativité, n'est quant à lui jamais exempt du mal et du défaut par essence ${ }^{67}$. Glosant la Métaphysique du Šifấ, Mīr Dāmād attribue l'origine de tout mal à la matière comme pure puissance, pour mieux en dispenser le monde intelligible désigné comme «le monde de la louange et de la glorification ( 'ālam al-taḥmìd wa-l-tasbịh) - conçu comme acte pur :

Toute chose existante dans sa complète perfection sans rien contenir qui soit en puissance n'est associée à aucun mal. Le mal est seulement associé à ce qui contient dans son naturel quelque chose en puissance, du côté de la matière portant la puissance dispositionnelle (al-quwwa al-isti'dādiyya). Le monde de la louange et de la sanctification est absolument exempt de tout aspect du mal. Moins une chose a en elle d'être en puissance, plus elle est exempte du mal ${ }^{68}$.

Mīr Dāmād précise toutefois que si le mal se dit de choses négatives ou participant de l'inexistence (umūr 'adamiyya) comme la mort, la pauvreté ou l'ignorance, il se dit aussi de choses participant de l'existence (umūr wuğūdiyya) comme l'injustice, l'adultère, les souffrances et les chagrins, en tant qu'elles empêchent l'existant d'atteindre sa perfection. Les premières correspondent chez Ibn Sīnā au mal en soi, les secondes au mal par accident ${ }^{69}$. Ces maux moraux, physiques ou psychologiques ne sont pas de pures négativités, mais des effets des facultés inférieures de l'âme, des mœurs viles et des complexions corporelles, lesquelles ont une réelle positivité dans le système de l'existence ${ }^{70}$. Partant, ce n'est jamais en tant qu'elles participent de l'existence que les réalités peuvent être dites mauvaises :

Nous trouvons que le froid, par exemple, n'est aucunement un mal en lui-même, que ce soit en tant qu'il est un certain mode d'être ou sous l'aspect de la raison qui le nécessite et des causes qui conduisent à lui. Bien plutôt, il est une des perfections du système de l'existence ; son mal n'est que relatif aux fruits dont il corrompt les semences. Le mal en soi est le fait que les fruits perdent les perfections qui leur sont associées. Le froid est un mal par accident, parce qu'il amène à ce qui est un mal. (...). De même encore, l'injustice et l'adultère, en tant qu'ils procèdent des deux puissances irascible et concupiscible (al-gáạabiyya wa-l-šahwiyya) de l'âme, ne sont en rien des maux ; bien au contraire, de ce point de vue, ce sont des

\footnotetext{
${ }^{67}$ Mīr Dāmād, Qabasāt, 430.

${ }^{68}$ Mīr Dāmād, Qabasāt, 431 ; Ibn Sīnā, Ilāhiyyāt al-Šifā’, éd. al-Ab Qanawātī et Sa‘̄ì Zāyid (Beyrouth: s.n., 1960$), 416$.

${ }^{69}$ Shihadeh, « Avicenna's Theodicy and al-Rāzì’s Anti-Theodicy », p. 65-66.

${ }^{70}$ Mīr Dāmād, Qabasāt, 431-432.
} 
perfections de ces puissances de l'âme. Le nom de mal ne leur est attribué que relativement à la victime de l'injustice ayant perdu son bien et sa perfection, à la règle juste de la politique civile dont l'ordre est dérangé par ce fait, ou à l'âme raisonnable pour son impuissance à contrôler ses puissances animales et son exil de la contrée de la lumière au gouffre des ténèbres (...). Le mal, en réalité, est le fait que l'une de ces choses perde son lot de perfection, sa part de bonheur et la splendeur de sa complétude. Ce n'est que par accident que l'on attribue le nom [de mal] aux causes conduisant à [cette perte] (...). De même [encore], les souffrances, parce qu'elles sont des perceptions de certaines choses, ne sont pas des maux, que ce soit parce que ces choses existent par elles-mêmes ou parce qu'elles procèdent de leurs causes. Leur mal n'est qu'accidentel, relatif à l'être souffrant ayant perdu la connexion normale de l'un de ses membres, [et seulement] en tant qu'il la perd ${ }^{71}$.

Sur la base d'une définition ontologique, le raisonnement par analogie aboutit ainsi à un nivellement du mal moral, tel celui causé par l'injustice, et du mal physique, tel celui causé par le froid. Reprenant la tripartition platonicienne de l'âme en intelligence ou raison (gr. noûs, ar. 'aqI), élément irascible (gr. thumos, ar. ġadab) et concupiscence (gr. epithumia, ar. šahwa), Mīr Dāmād en tire des conséquences audacieuses : les passions, en tant qu'expressions des parties inférieures de l'âme, ne sont pas mauvaises en elles-mêmes et possèdent même une valeur de perfection; elles ne sont mauvaises que du point de vue de l'âme rationnelle, de son aspiration à la perfection suprasensible et de sa vocation naturelle à dominer les puissances animales. De même, ce n'est que du point de vue de l'ordre politique, qui prédomine naturellement sur l'individu, que la débauche de celui-ci peut être jugée mauvaise. La relativisation de la morale n'entraîne donc nullement une remise en cause de l'ordre social et une disqualification du droit pénal, ce qui serait bien étonnant de la part d'un homme d'État et d'un juriste comme Mīr Dāmād. Mais il faut admettre que la désignation de choses ou d'actes comme mauvais ne correspond qu'à une vision parcellaire de la réalité, quand une appréhension totale et objective de la réalité - « sous un aspect d'éternité » (sub aeternitatis specie) comme le disait Spinoza ${ }^{72}$ - ne voit plus que le Bien :

Les existants en tant qu'existants, parcelles du système de l'existence, ne sont aucunement des maux. Les maux de ce monde ne sont que des affaires relatives, rapportés à certains individus déterminés, séparés de l'ordre universel qui intègre et accorde toutes choses. Considérés en eux-mêmes et rapportés au tout, ils ne contiennent absolument aucun mal. Si quelqu'un pouvait embrasser l'ensemble du système de l'existence, observer toutes les causes conduisant aux choses causées, selon l'ordonnancement longitudinal et latitudinal descendu du Principe du Tout, il verrait toute chose sous l'aspect qui convient à l'existence et à la perfection visée par le système ; il ne verrait plus aucun mal, sous aucun aspect, dans l'existence selon la

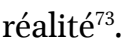

\footnotetext{
${ }^{71}$ Mīr Dāmād, Qabasāt, 432.

${ }^{72}$ Spinoza, Éthique, partie II, proposition XLIV, corollaire II, 184-185.

${ }^{73}$ Mīr Dāmād, Qabasāt, 432-433. Source : al-Tūsī, Šarh, vol. 3, 320-321.
} 
Reste à savoir si cette compréhension universelle englobant à la fois l'ordre «longitudinal», soit la hiérarchie verticale des hypostases néoplatoniciennes - l'Un-Réel divin, l'Intellect, l'Âme, la Nature -, et l'ordre « latitudinal » du système de l'existence, soit le plan horizontal de la physique aristotélicienne, est accessible à l'homme. À l'évidence, en effet, une telle compréhension est bien proche de la sagesse divine théorique définie dans l'introduction du Šări' al-nağăt.

Mīr Dāmād procède à une division analytique des êtres du point de vue de la présence ou de l'absence de mal, c'est-à-dire de négation ou d'inexistence, en eux. Il en ressort cinq catégories : 1. Ce qui ne contient aucun mal relatif: l'existence en acte absolument bonne, effusant nécessairement de la Prodigalité divine. Ce sont les substances intellectives qui ne contiennent rien qui soit en puissance et ne rivalisent en rien les unes avec les autres. Le monde intelligible ne contient donc que du bien. 2. Ce en quoi le bien l'emporte sur le mal : les bienfaits du système de l'existence, effusant nécessairement de la Providence primordiale, accompagnés de maux mineurs, comme le froid, dont l'exemple a été vu, ou le feu qui ne peut servir la complétude du système de l'existence sans nuire à quelques corps à l'occasion de rencontres fortuites. Le monde naturel contient donc un maximum de bien pour un minimum de mal, qu'il soit physique ou moral. 3. Le mal relatif sous tous les aspects. 4. Ce en quoi le mal prédomine. 5. Ce en quoi le bien et le mal s'égalisent. Le philosophe affirme que ces trois dernières catégories n'ont qu'une existence mentale (wuğūd dihnì) - par opposition à une existence extérieure (fi l-hâariğ) ou positive - dans le monde de la Détermination, car «il est absolument impossible qu'elles procèdent du Bien en soi, du Tout-Effusant par la Providence, du Tout-agissant par Sagesse accomplie $»^{74}$.

Le mal n'a donc qu'une existence inessentielle, relative à une minorité de choses de valeur modique. Il n'entre dans le Décret primordial ( al-qaḍā' al-awwal) que par accident, en tant qu'il est le concomitant du Bien surabondant effusant sur la plupart des existants et la plupart du temps. Ayant appliqué ce principe au mal historique à travers le concept de badā', Mīr Dāmād doit aussi l'appliquer aux maux de la vie dernière (šurūr našat al-ma'âd). En effet, la réparation promise du mal historique pose désormais le problème de la Justice divine sous un autre aspect que celui de la liberté ou de la responsabilité traité dans la Risālat al-Īqāāàt: si les maux commis par les hommes ne sont que des concomitants accidentels de bienfaits essentiels, comment justifier le châtiment final des pécheurs? La première réponse approfondit un argument formulé dans l'épître susmentionnée :

La misère de l'âme dans la substance de son essence du fait de l'ignorance redoublée, sa misère due au corps et à la chute dans le remous de la concupiscence ou de la colère, par exemple, suivent la voie de tous les maux minoritaires concomitants des bienfaits nombreux visés par la Providence primordiale. De même, les châtiments divins dans la vie dernière entrent dans le Décret et la Détermination en tant qu'ils sont les concomitants des bienfaits du système de l'existence, résultent de leurs moyens et font partie des causes finales de l'imputation (takliff) selon les lois de la sagesse dans cette vie, car sans la dissuasion et la menace de ces châtiments, les âmes des sujets d'imputation (al-mukallafin) ne pourraient s'abstenir du

\footnotetext{
${ }^{74}$ Mīr Dāmād, Qabasāt, 433-434, 435 ; al-Ṭūsī, Šarh, vol. 3, 321-322; Shihadeh, « Avicenna's Theodicy and al-Rāzīs AntiTheodicy $», 67$.
} 
péché et de la désobéissance. La mise à l'exécution [des menaces] est une cause finale de cette abstention ; un manquement [à ces menaces] entraînerait un défaut dans la Sagesse. De même que l'action de l'homme, sa volonté et son choix, en vertu du Décret et de la Détermination de Dieu (...), sont conformes aux dispositions des matières et aux mérites des quiddités, de même la récompense et le châtiment, en vertu du Décret et de la Détermination, sont des concomitants des quiddités des actions et des œuvres bonnes et mauvaises, avec leurs différents degrés de beauté et de laideur essentielles. La récompense et le châtiment ne reviennent qu'à l'agent, sujet d'initiative par volonté et choix, bien qu'il ne soit pas la cause finale nécessitant cet acte, mais parce qu'il en est le substrat récepteur, tout comme les remèdes opiacés et les poisons ne manifestent leurs propriétés et leurs effets que dans les corps et les complexions de ceux qui les ingèrent. La médecine spirituelle suit ici la voie de la médecine corporelle et les remèdes spirituels celle des remèdes corporels ${ }^{75}$.

On comprend que les bonnes et les mauvaises actions entraînent aussi nécessairement leur rétribution - récompense ou châtiment - que l'ingestion de remèdes ou de poisons entraîne nécessairement la santé ou la mort, ce qui pointe vers l'idée d'une justice immanente, pour ainsi dire automatique, qui pour être conforme aux principes philosophiques de notre auteur, contrevient au dogme exotérique du Jugement transcendant de Dieu. L'intention de Mīr Dāmād est pourtant « orthodoxe » : justifier la rétribution du mal par le mal comme une «médecine spirituelle», aussi bien de la part de Dieu, s'appliquant au système de l'être, que de la part des juristes, s'appliquant au corps politique. Plus encore, selon les Talīqät d'Avicenne :

N'était-ce une seule chose partielle à laquelle conduisent les causes, fût-elle répréhensible par la raison, comme le larcin du voleur ou l'adultère du fornicateur, le système du monde ne serait pas conservé. Par suite, le châtiment qui afflige le fornicateur ou l'oppresseur ne lui advient que pour la conservation du système universel. Si les rétributions des bonnes actions comme des mauvaises n'étaient pas attendues, le système universel ne se conserverait pas $^{76}$.

Crimes et châtiments se voient justifiés du même coup comme conjointement nécessaires à l'ordre de l'existence. Le raisonnement vaut aussi bien pour le monde d'ici-bas et les châtiments temporels prononcés par les juristes que pour la vie dernière et les châtiments éternels ordonnés par Dieu. Sur le plan métaphysique du système de l'existence, le châtiment des damnés est un moindre mal pour un maximum de bien, tout comme l'est, sur le plan politique, la répression du vice. Ainsi, si pour le philosophe, la connaissance de la Sagesse divine est à elle-même sa propre fin, la théodicée, chapitre essentiel de cette théologie véritable, apparaît aussi comme le fondement ultime de la politique et du droit pénal.

Mīr Dāmād cite encore un passage des Išārāt d'Avicenne commenté par Ṭūsī : « Si l'on demande : «Si c'est la Détermination [divine], pourquoi le châtiment ? », je réponds : « Le châtiment de l'âme en raison de sa

\footnotetext{
${ }^{75}$ Mīr Dāmād, Qabasāt, 437. La fin du passage est identique à İqāzāt, 12, passage cité supra.

${ }^{76}$ Mīr Dāmād, Qabasāt, 438 ; Ibn Sīnā, Ta līqāt, 47 B, 110 M..
} 
faute est comme la maladie advenant au corps en raison de sa voracité : un concomitant nécessaire auxquels ont conduit les états passés; il ne peut pas ne pas advenir, comme ce qui s'ensuit ne peut pas ne pas advenir ${ }^{77}$. » Voilà qui enlève tout arbitraire à la Rétribution divine comme, potentiellement, à la justice pénale des hommes. Mais en contrepartie, on se demande quelle est encore la part de la libre volonté, qu'elle soit divine et absolue ou humaine et relative, dans l'exercice de la justice rétributive. L'idée d'une justice immanente, résultant de l'enchaînement nécessaire des actes et de leurs effets, se conjugue difficilement à celle d'une Justice transcendante, rendue par un Dieu absolument libre et tout-puissant. Mīr Dāmād se garde bien de relever un tel problème. Suivant sa même intention apologétique, il insiste plutôt sur le bénéfice individuel et universel de la menace et du châtiment :

L'existence de la dissuasion (al-taḩwīf), concernant des choses qui sont assurément des causes du châtiment (...), est belle et nécessaire pour son utilité à la plupart des individus et la plupart du temps ; c'est grâce à elle que [les individus] s'abstiennent de commettre crimes et péchés. L'exécution de la menace, sa réalisation par le supplice du criminel, confirme la dissuasion et entraîne un surcroit d'utilité ; elle est donc également belle et nécessaire, suivant la Sagesse accomplie et la Providence primordiale de Dieu. (...) Le maître [Avicenne] a expliqué que ce châtiment n'était un mal que du point de vue du criminel châtié, mais qu'il était un bien du point de vue des individus de son espèce et de la perfection de l'état de l'espèce. « L'on n'accorde pas d'importance au point de vue particulier vis-à-vis de l'universel », car cela appartient aussi au Bien surabondant dont la totalité a pour concomitant un mal modique, comme l'illustre l'amputation d'un membre pour la santé du corps entier ; bien que l'acte englobe quelque mal, le jugement qu'il est nécessaire est admis par la masse ${ }^{78}$.

Que le bien du tout prime sur le bien de la partie, comme quand on ampute un membre pour sauver le corps, était déjà un principe pour une philosophie aussi optimiste et une éthique aussi rigoureuse que celles du stoïcisme antique $^{79}$. Mīr Dāmād insiste d'ailleurs, avec Nașîr al-Dīn al-Ṭūsī, sur l'accord des enseignements de la Révélation avec les principes philosophiques (al-uṣull al-hikmiyya) et les règles de la raison ${ }^{80}$. C'est pourquoi il fait droit à une double objection formulée par le « guide des sceptiques » Fahr al-Dīn al-Rāzī. Premièrement, tout comme l'on peut demander : «Si l'acte dépend de la Détermination, pourquoi le châtiment ? », on pourrait demander : «Si l'acte dépend de la Détermination, pourquoi la dissuasion ? ». Deuxièmement, la réponse serait acceptable si et seulement si le nombre de châtiés (al-mu'adddabūn) était moindre que le nombre de sauvés ; mais selon l'orthodoxie islamique, les damnés (al-hālikūn) sont plus nombreux que les sauvés ${ }^{81}$.

\footnotetext{
${ }^{77}$ Mīr Dāmād, Qabasāt, 439 ; Ibn Sīnā, Išārāt 337 ; Avicenne, Livre des directives et des remarques, 463-464 ; al-Ṭūsī, Šarh, vol. $3,328$.

${ }^{78}$ Mīr Dāmād, Qabasāt, 440-441.

${ }^{79}$ Voir Épictète, Entretiens, trad. Jean Souilhé (Paris, Gallimard-Tel, 1993), 112.

${ }^{80}$ Mīr Dāmād, Qabasāt, 441.

${ }^{81}$ Mīr Dāmād, Qabasāt, 442.
} 
À la première objection, Ṭūsī répond que la dissuasion fait elle-même partie des causes déterminant la bonne action $^{82}$. Mīr Dāmād ajoute que la doctrine des sages philosophes à ce sujet est la même que celle des Imâms impeccables du shi'isme : l'homme est l'agent et le sujet d'initiative de son acte par sa capacité, sa volonté et son choix, lesquelles adviennent de causes remontant finalement à la capacité, à la volonté et au choix de Dieu. Concluant par la formule : «Ni déterminisme ni liberté absolue mais quelque chose entre les deux », il renvoie à ses $\bar{I} q a \bar{a} z \bar{a} t$ pour plus d'explications ${ }^{8_{3}}$.

Concernant la seconde objection, notre philosophe contredit la défense de Ṭūsī. Avec Rāzī, il tient en effet pour évident que les sauvés sont en moindre nombre que les damnés ${ }^{84}$, ce qu'il s'emploie à justifier au nom de la perfection du système :

Le mélange apte à la perfection de la substance de l'âme, la disposition conduisant à la purification de ses puissances et au perfectionnement de ses facultés et de ses mœurs, se réalisent dans un petit nombre de compositions matérielles. Ceci est clairement énoncé par la langue de la sage Révélation comme par celle des hadīts des législateurs. Il est donc juste de dire que si les damnés sont plus nombreux, cela fait partie des concomitants de bienfaits extrêmement nombreux au regard de la perfection de l'espèce et de ses individus sauvés. (...) Si l'existence des damnés n'entrait pas dans le Décret et la Détermination, cela aurait pour concomitant l'inexistence des causes ayant abouti à elle, la corruption du système universel, la privation de l'espèce de sa perfection ultime possible, la non-venue à l'existence des âmes humaines sanctifiées, la suppression radicale de l'existence des individus sauvés, tant il est vrai que l'existence des damnés fait partie des concomitants du système existant (...). Le mal consistant dans leur nonexistentiation serait infiniment pire que le mal résultant de leur damnation. Il est donc attesté que leur existentiation, exigeant leur châtiment et leur damnation dans la vie dernière, est un mal négligeable et modique par rapport aux biens immenses et nombreux qu'elle nécessite dans le système de l'existence ${ }^{85}$.

Ce texte représente le point ultime de la théodicée de Mīr Dāmād comme effort de résoudre philosophiquement et théologiquement, du point de vue shicite imâmite, le problème du mal. Il maintient que toutes les souffrances infligées et endurées, dans cette vie comme dans la vie dernière, sont les concomitants et les conditions du plus grand bien qu'est la réalisation de la perfection humaine et le salut des âmes purifiées. Ces âmes purifiées sont celles des imâms, des shi'ites initiés ou «croyants au cœur éprouvé par Dieu pour la foi ${ }^{86}$, ainsi que des sages ( 'urafā $)$ « enracinés dans la science ». Elles ne peuvent que demeurer en nombre très

\footnotetext{
${ }^{82}$ Mīr Dāmād, Qabasāt, 442 ; Faḩr al-Dīn al-Rāzī, Šarḥ al-Ǐ̌ārāt, éd. s.n., 2 vols. (Qom : Maktabat Āyatullāh Mar'ašī, 1404/1983-4), vol. 2, 562 .

${ }^{83}$ Mīr Dāmād, Qabasāt, 443.

84 Telle était aussi la position de Leibniz qui, rejetant la doctrine origéniste du salut universel, affirme s'en tenir «à la doctrine établie, que le nombre des hommes damnés éternellement sera incomparablement plus grand que celui des sauvés. » (Essais de théodicée, 114).

${ }^{85}$ Mīr Dāmād, Qabasāt, 443.

${ }^{86}$ Selon un fameux hadīt attribué à différents imâms : « Notre enseignement est ardu, extrêmement difficile ; seul peut le supporter un prophète envoyé, un ange rapproché de Dieu ou un croyant dont le cœur a été éprouvé par Dieu pour la foi ».
} 
minoritaire, à l'inverse des âmes impures nécessitant leur châtiment comme un remède spirituel ; plus encore, la domination quantitative des damnés, vicieux et malfaisants ici-bas, apparaît nécessaire à l'émergence d'une minorité d'êtres parfaits. Toute la capacité maléfique de l'homme, toute la tragédie de l'histoire, toute la dureté du châtiment divin, autant d'éléments d'un pessimisme religieux que Mīr Dāmād ne cherche nullement à adoucir, se voient ainsi justifiées par la Sagesse de Dieu, la Providence génératrice de l’Homme parfait.

Si cette théodicée s'efforce d'appliquer les principes de la philosophie néoplatonicienne et avicennienne à la conscience religieuse du shi'isme imâmite et représente de ce point de vue un authentique essai de philosophie shi'ite, on ne peut qu'être frappé par l'absence criante, dans cette justification eschatologique du mal moral et historique, de référence au douzième imâm, le Mahdī qui, selon la tradition, doit venir peu avant la fin des temps «couvrir la terre de justice comme elle l'aura été d'injustice ${ }^{87}$. Son combat sans merci, au côté des purs martyrs de l'histoire sainte shicite et contre leurs pires ennemis, tous ressuscités pour l'occasion - c'est la doctrine du ră̆a -, viendra justifier en acte tous les maux subis par les imâms et leurs shi'ites et établir un bref règne final du bien sur terre ${ }^{88}$. Mais cette doctrine messianique n'était pas à l'ordre du jour dans l'État shi'ite safavide de Šāh 'Abbās (r. 996-1038/1588-1629) et Šāh Șafĩ (r. 10381052/1629-1642), dont Mīr Dāmād était un proche dignitaire, quoique cette dynastie fut elle-même issue d'un mouvement messianique, et précisément en raison de sa nécessaire routinisation ; les traditions sur le retour du Mahdī, si présentes dans les anciens recueils et la doctrine originelle, passaient désormais pour l'apanage des «exagérateurs » ou «extrémistes » $(\dot{g} u l a ̄ t){ }^{89}$. D’autre part, en tant que juriste-théologien, Mīr Dāmād appartenait au courant rationaliste ușūlī promouvant l'autorité du savant apte à l'interprétation de la loi, le muğtahid, en lieu et place de l'imâm absent, contre les traditionnalistes ah̆bārīs affirmant la seule autorité de l'imâm et attachés à la conservation des hadịts les plus ésotériques. Enfin et surtout, la métaphysique du temps et de l'éternité et la conception du Retour à l'Un (al-ma‘ād) de Mīr Dāmād ne pouvaient qu'interdire, en la neutralisant, l'interprétation temporelle et politique de l'eschatologie shicite ${ }^{90}$. Ce n'est pas pour considérer la pensée de Mīr Dāmād comme une superstructure idéologique mais pour souligner à nouveau la solidarité de ses facettes philosophique et juridico-politique. Cette occultation du Mahdī dans la théodicée de Mīr Dāmād est donc cohérente avec son contexte théologico-politique comme avec tout son système philosophique, bien qu'une philosophie shi'ite sans mahdisme demeure un paradoxe.

\section{Essais de théodicée chez deux élèves de Mīr Dāmād}

\footnotetext{
Voir là-dessus M. A. Amir-Moezzi, Le Guide divin, index, s.v. imtihāan (al-qalb).

${ }^{87}$ Parmi les nombreuses sources anciennes : al-Kulaynī, Ușūl, K. al-Huğğă, bāb al-g்ayba, 197, ḥ. 7 ; Ibn Abī Zaynab alNu'mānī, Kitāb al-Ǵayba, éd. Muḥammad Ğawād al-Ġaffārī (Téhéran : Dār al-kutub al-islāmiyya, 139o h.s./2011-12), bāb 4, ḥ. $2,91$.

${ }^{88}$ Sur le combat final du Mahdī, voir M. Terrier, « Le combat sacré », 29-31.

${ }^{89}$ Sur les origines des Safavides, voir Michel M. Mazzaoui, The Origins of the Safawids (Shi'ism, Sufism and the Ghulât) (Wiesbaden : Franz Steiner, 1972). Sur le processus de routinisation, voir Said Amir Arjomand, The Shadow of God and the Hidden Imam (Londres : The University of Chicago Press, Chicago - Londres, 1984), 105-214.

${ }^{90}$ C'est ainsi que Christian Jambet interprète la « politique de la pensée » de Mullā Șadrā dans La fin de toute chose, suivi del'Épître du Rassemblement de Mullâ Sadrâ (Paris : Albin Michel, 2017), 183-198.
} 
Si l'on trouve, chez Mullā Ṣadrā et son élève Mullā Muhsin al-Fayḍ al-Kāšānī, d'autres développements sur la théodicée, intégrant notamment des éléments de doctrine akbarienne (du šayh al-akbar Ibn 'Arabīi ${ }^{91}$, nous suivrons les prolongements des idées de Mīr Dāmād chez deux autres élèves bien moins connus : Mullā Šamsā Gīlānī (m. 1064/1654) et Quṭb al-Dīn Aškevarī (m. entre 1088/1677 et 1095/1684).

\section{«Le mal pur n'advient pas dans le monde de l'existence »: théodicée et ontologie chez Mullā Šamsā} Gīlānī

Mullā Šamsā consacra à la question du mal une épître en persan intitulée Izăār al-kamāl (La manifestation de la perfection $)^{92}$. Son approche est purement métaphysique et ontologique, sans aucune référence historique ni conséquence politique. On note aussi l'absence de traditions imâmites ésotériques dans son texte, ce qui lui permet une spéculation beaucoup plus binaire et moins paradoxale que celle de son maître. Son point de départ est une double définition axiomatique de la perfection et de l'imperfection :

La perfection est le bien qui influe (mu'attirir), l'imperfection est le mal qui repousse. C'est pourquoi la perfection de chaque existant est ce qu'il recherche, ce qui le réjouit et l'enchante, tandis que son imperfection est ce qu'il fuit et dont il souffre. La perfection est de deux sortes : l'une est la manifestation et

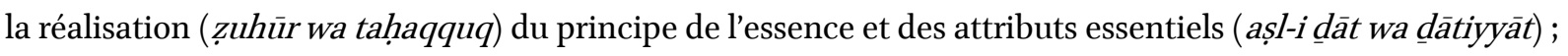
l'autre est la manifestation de la parure (zinnat) de l'essence et des attributs essentiels. L'imperfection (...) est donc aussi de deux sortes : l'une est la négation de la manifestation et de la réalisation de l'essence et des attributs essentiels; l'autre est la négation de la réalisation de la parure de l'essence et des attributs essentiels. Par suite, la réalité de l'imperfection relève de l'inexistence, et l'imperfection absolue est l'inexistence de l'essence et des attributs essentiels (...). La réalité de la perfection, elle, relève de la manifestation, de la réalisation et de l'existence ${ }^{93}$. [...]

Aucun existant ne possède d'imperfection en tant qu'il est existant, puisque la réalité de l'imperfection est l'inexistence. Oui, il arrive qu'une chose existante soit accompagnée d'imperfection, au sens où elle ne contient pas l'existence de la parure de son essence et ce qui convient à celle-ci. Dans ce cas, la chose existante en tant qu'existante n'est pas un mal par essence et en réalité, mais elle est accompagnée

\footnotetext{
${ }^{91}$ Sur al-Fayḍ al-Kāšānī, Mathieu Terrier, «La Rétribution finale en islam : discussions sur l'imputation des actes et la perpétuité des peines », dans David Hamidovic, Apolline Thromas et Matteo Silvestrini (dir.), 'Retribution' in Jewish and Christian Writings: a Concept in Debate (Tübingen : Mohr Siebeck, 2019), 123-148.

${ }^{92}$ Voir Henry Corbin, La philosophie iranienne islamique aux XVII et XVIII siècles (Paris : Buchet-Chastel, 1981), 134-140. Sur Mullā Šamsā Gīlānī et son lien avec Mīr Dāmād, voir Sajjad Rizvi, «Mullā Shamsā Gīlānī and his Treatise on the Incipience of the Cosmos (hudūth al-ălam) », Ishraq (Islamic Philosophy Yearbook) 6 (Moscou : Nauka - Vostochnaya Literatura, 2015), 40-70.

${ }^{93}$ Mullā Šamsā Gīlānī, Iẓhār al-kamāl, dans Sayyid Ğalāluddīn Āštiyānī (éd.), Anthologie des philosophes iraniens du XVII jusqu'à nos jours, 4 vols. (Téhéran-Paris : Institut Français de Recherche en Iran - Librairie d'Amérique et d'Orient AdrienMaisonneuve, 1972-1978), vol. 1, 437-446, 437.
} 
par le mal. La mauvaiseté de ce qui est accompagné par le mal est une mauvaiseté par accident, non par essence $^{94}$.

Mullā Šamsā tire ainsi les conséquences radicales du principe reçu d'Avicenne et de Mīr Dāmād selon lequel le mal ne peut avoir aucune positivité. Ceci l'amène à assimiler de même manière le mal moral au mal physique, mais il va plus loin en traitant du mal personnifié en Satan :

Par suite, tout ce qui entre dans le monde de l'existence et n'est pas inexistant ne peut se voir attribuer réellement le mal en soi ; bien au contraire, tout ce qui est ainsi est un bien en soi (...). Si le mal est attribué à une chose existante, c'est en tant qu'elle est accompagnée par le mal en soi, non en tant qu'elle serait un mal en soi. Par exemple, une douleur qui advient à un membre, en tant que la douleur existe dans ce membre, n'est pas un mal en soi. Mais la douleur est mauvaise si l'on considère qu'elle est accompagnée du mal en soi qui est la négation de la tranquillité du corps comme de plusieurs choses qui lui sont convenables. De même, l'existence de la haine, de la jalousie, de la rancune et de l'hypocrisie n'est pas un mal en soi et l'on ne peut pas réellement les qualifier de maux en soi ; non, mais elles sont mauvaises parce qu'elles sont accompagnées du mal en soi. En effet, l'existence de la haine, de la rancune et de l'hypocrisie est accompagnée de la négation de la perfection de l'âme, de la parure de l'essence de l'âme et de ce qui lui convient.

De même, l'existence du Satan n'est pas le mal en soi et le mal ne peut pas vraiment lui être attribué. Sa mauvaiseté est accidentelle en ce sens qu'il est accompagné du mal en soi. Car l'existence du Satan n'est pas seulement accompagnée de l'inexistence de la parure de son essence et de ce qui lui convient, mais aussi de l'inexistence de la parure de l'essence d'autres existants et de ce qui leur convient. Parce que l'existence du Satan est accompagnée de maux en soi innombrables dépassant toute mesure, on s'est imaginé que l'existence du Satan était le mal en soi. De même, l'existence du serpent et de son venin n'est pas un mal en soi, car le venin est ce qui convient à l'existence et au tempérament du serpent (...) L'erreur ne naît que de l'absence de distinction entre ce qui est accompagné du mal en soi et le mal en soi lui-même.

Par cette analyse, il est connu que le mal en soi n'est rien que l'inexistence, que le bien en soi n'est rien d'autre que l'existence, la perfection de l'existence et la parure de l'existence. De là ce que les sages ont dit : «Le bien, c'est l'existence ; le mal, c'est l'inexistence ${ }^{95}$.

Cette formule attribuée aux sages en général ne se trouve à la lettre dans aucune source philosophique, mais apparaît comme une paraphrase condensée du propos de Mīr Dāmād cité plus haut : «L'existence est tout

\footnotetext{
${ }^{94}$ Mullā Šamsā Gīlānī, Iẓhār, 438.

${ }^{95}$ Mullā Šamsā Gīlānī, Iẓhār, 439-440.
} 
entière un bien, le mal est tout entier inexistence $»^{96}$. Plus loin, Mullā Šamsā paraphrase encore son ancien maître sous l'autorité des deux références scripturaires que contient cette épître :

Dans le Tout-Effusant absolu (fayyạ̄̂-i muțlaq), il n'y a aucune avarice. Il est le Bien pur et « du bien pur ne peut venir que du bien ». Par suite, le défaut et l'imperfection advenant en réalité proviennent du récepteur et non de l'agent, car tout ce qui vient de l'agent est bon. Il est probable que la parole de Dieu : « Tout bien qui t'arrive vient de Dieu, tout mal qui t'arrive vient de toi» (IV, 79), soit une indication de ce que nous avons expliqué, tout comme une prière votive transmise par une lignée ininterrompue de témoins $\left(d u^{\prime a}-y i\right.$ ma'tür $):$ «L bien est entre Tes mains mais le mal ne Te revient pas $»^{97}$.

Remarquons dans cet extrait la reformulation du principe hénologique du néoplatonisme : «De l'un ne provient que de l'un» (ех ипо non fit nisi unum) en un principe plus rigoureusement platonicien et surtout plus adéquat à l'entreprise de théodicée : «Du bien ne provient que du bien $»^{98}$. Mullā Šamsā entreprend ensuite de réfuter un «célèbre sophisme» apparemment tourné contre le Dieu des philosophes, «l'Être nécessaire par soi » d'Avicenne :

Comme nous voyons dans le monde de l'existence beaucoup de débauche, de dérèglement, de pillage, de meurtre illégal, il y a lieu de dire : «Ce monde regorge de maux et de fléaux, en tout temps et à tous moments. Ainsi, de même que le bien est dans ce monde, le mal l'est aussi. Or, Celui qui a donné existence à ces deux choses [le bien et le mal] est [un être] unique, car il est prouvé par la raison et la tradition (bih burhān-i 'aqlī wa naqlì) que l'effusion de l'existence, de la réalité, de la perfection de l'existence et de la perfection de la réalité, est exclusive à l'Être nécessaire par soi ( wāğib al-wuğūd bi-l-d̄āt). Il n'y a pas d'autre Existentiateur que l'Être nécessaire unique. Il est donc nécessaire qu'Il soit, Lui et nul autre, l'existentiateur du bien et du mal en soi $»^{99}$.

Là encore, pour notre philosophe, l'erreur naît de la confusion entre le mal en soi et ce qui est accompagné du mal en soi. Ayant établi que les vices n'ont en soi rien de mauvais, il peut affirmer que même le meurtre illégal n'est pas un mal en soi mais est seulement accompagné du mal pour l'être tué et l'ordre social ${ }^{100}$. Sans apporter d'argument nouveau, il reformule de la façon la plus claire les attendus de la théodicée philosophique: «Nous avons prouvé qu'il est impossible qu'il y ait un système meilleur, plus parfait, plus

\footnotetext{
${ }^{96}$ Mīr Dāmād, Qabasāt, 428.

${ }^{97}$ Mullā Šamsā Gīlānī, Iẓhāar, 441. Le hạaît cité à la fin est attribué au prophète Muhammad par les sources sunnites et à l'imâm Ğa'far al-Ṣādiq par le traditionniste shicite de l'époque safavide al-Mağlisī, Bịhār, vol. 81, 366, ḥ. 21. Nous le retrouverons cité chez le dernier penseur étudié dans cet article.

${ }^{98}$ Dans la République de Platon (livres VI-VII), c'est le Bien en soi qui est au sommet du monde intelligible et apparaitt comme le principe de toute chose. Plotin, se basant plutôt sur le Parménide de Platon, substituera l'Un au Bien.

${ }^{99}$ Mullā Šamsā Gīlānī, IẒhār, 443 .

${ }^{100}$ Mullā Šamsā Gīlānī, IẒhār, 444.
} 
complet et plus noble que le système existant en réalité. Par suite, l'acte du Réel divin ne comprend aucune erreur ou imperfection, tout ce qu'll fait est bien pur et le mal pur n'advient pas dans le monde de l'existence $»^{101}$.

Le monde est donc bien, comme le pensera Leibniz, le meilleur des mondes possible. Plus encore, pour Mullā Šamsā, il n'y a même pas à concevoir l'existence d'un moindre mal pour un maximum de bien : « Le mal en soi et le laid en soi n'entrent pas dans le monde de l'existence, parce que tout ce qui est dans le monde de l'existence est bon et beau, dépendant qu'il est de l'Instauration ( $\breve{g} a$ `) et de l'Influx (ta'tīir) de Dieu Très-Haut. Car si le mal en soi et le laid en soi étaient présents dans le monde de l'existence, ils seraient nécessairement dépendants de l'Instauration et de l'Influx de Dieu. Or il n'en est pas ainsi, donc il n'en est pas ainsi » ${ }^{102}$.

Le mal n'a donc pas son origine ou son principe dans l'Instauration, l'Effusion ou l'Existentiation qui sont les modes d'action essentiels de Dieu. Cette thèse rompt apparemment avec la tradition imâmite originelle et les hadịts évoqués en introduction sur la création première ou seconde du mal, pour se rapprocher de celle, shi'ite ismaélienne, que nous rencontrerons chez Quṭb al-Dīn Aškevarī. Mullā Šamsā Gīlānī pourrait s'arrêter là tant il semble avoir synthétisé et parachevé l'essai de théodicée de son maître. Mais il effectue un pas de côté par rapport à la tradition philosophique en proposant une nouvelle interprétation d'un hadīị qudsī souvent médité par les soufis :

Étant connu que Dieu effuse l'existence dans l'absolu, qu'il n'y a aucune avarice dans le principe effusant, que Son œuvre est de donner l'existence, la réalité, les perfections d'existence et de réalité, et qu'Il effuse sans aucun défaut sur tout ce qui est apte à recevoir quelque part de Son Effusion, le sens du hadīt saint: «J'étais un trésor caché et j'aimais à être connu. Alors Je créai les créatures afin d'être connu » devient manifeste. L'Être nécessaire (...) étant absolument effusant et libéral, Son effusivité et Sa libéralité absolues se sont manifestées avec Ses dons et Ses présents les plus immenses que sont les dons de l'existence, de la réalité, des perfections d'existence et de réalité. Par suite, il est nécessaire qu'advienne tout ce qui possède une force d'existence, depuis le domaine de l'occultation véritable en elle-même (az hayyiz-i hafä-yi haquìqĩ fì nafsihì) qu'est cette inexistence, par la pure effusion de la réalité de l'existence, dans le domaine de la manifestation qu'est ce monde de l'existence. Une fois advenu le monde de l'existence, Dieu se connut Lui-même. Cette connaissance suivit l'existence du monde du possible ; avant l'existence de ce monde, cette part de la connaissance de Dieu n'était pas. De ce point de vue, l'on peut dire que Dieu TrèsHaut était un trésor caché, c'est-à-dire qu'à part Lui, nul ne connaissait ce trésor de perfections éternelles et immuables ${ }^{103}$.

Mullā Šamsā semble ici reprendre une thèse fréquemment formulée par Mīr Dāmād, selon laquelle les essences ou quiddités sont précédées par une «pure inexistence » (al-'adam al-ṣarīḥ) et adviennent par une

\footnotetext{
${ }^{101}$ Mullā Šamsā Gīlānī, IẒhār, 445 .

${ }^{102}$ Mullā Šamsā Gīlānī, IẒhār, 446.

${ }^{103}$ Mullā Šamsā Gīlānī, Ị̇hhār, 446.
} 
« advenue perpétuelle ou méta-temporelle » $(\underline{h u d u ̄ t} \underline{t} d a h r i)^{104}$. suggère ici la thèse inquiétante que le mal en soi, qui est l'inexistence pure, est aussi bien l'origine des existants, le «domaine de l'occultation véritable en soi » d'où Dieu extrait les existants en fonction de leurs capacités à recevoir son effusion et son effectuation. Ceci rejoint Avec l'identification expresse de l'inexistence au mal, la création ex nihilo devient une création à partir du mal. De ce mal, Dieu Lui-même a voulu se sortir en créant les créatures afin de Se connaître. Le mal est donc aussi et d'abord l'ignorance de l'Essence divine, une ignorance qui semble avoir touché non seulement les existants possibles, mais Dieu Lui-même avant la création. Dès lors, la sagesse de Dieu est l'effort continu de connaissance de Son Soi par Son Soi à travers l'effusion et l'effectuation des existants, contre l'ignorance de Soi et l'inexistence des êtres. C'est dire que Dieu est dispensé de tout mal mais aussi que le mal, à la différence de la création, Lui est coéternel.

\section{« Le mal n’a pas son origine dans l'Instauration » : théodicée shi'ite et sagesse antique chez Quṭb al- Dīn Aškevarī}

Quṭb al-Dīn Aškevarī (m. entre 1088/1677 et 1095/1684) est principalement l'auteur d'une grande histoire de la sagesse en trois volumes : le premier consacré aux sages, prophètes et philosophes préislamiques ; le deuxième aux savants, philosophes et mystiques de l'Islam shicite comme sunnite; le troisième aux douze imâms et à autant d'autorités savantes du shi'isme imâmite, dont la dernière n'est autre que Mīr Dāmād ${ }^{105}$. Le premier volume contient deux brefs essais de théodicée attribués à deux figures assez inattendues, Diogène le Cynique et Zoroastre. Le premier, présent dans de nombreuses histoires des sages ${ }^{106}$, est plutôt réputé pour sa sagesse pratique et ses exploits ascétiques que pour ses spéculations théologiques. Aškevarī rapporte pourtant l'exposé doxographique suivant, emprunté au Livre des religions et des sectes (Kitāb al-Milal wa-l-niḥal) de 'Abd al-Karīm Šahrastānī (m. 548/1153), hérésiographe ash'arite et crypto-ismaélien :

Diogène faisait partie des philosophes qadarites [partisans du libre-arbitre] (...) Il dit : « Dieu Trèshaut n'est pas la cause des maux, mais il est la cause des biens, des vertus, de la générosité et de l'intelligence, qu'll a instaurés parmi Ses créatures. [L'homme] qui les acquiert et s'attache à [ces vertus], les donne [à d'autres], car il ne peut saisir les biens que par elles. » Je dis que le propos de ce sage correspond à

\footnotetext{
${ }^{104}$ Mīr Dāmād, Qabasāt, de nombreuses occurrences, notamment 19, 24, 26, 112-113, 167-168, 224-226, 242-244, 295-296, 421, 429. Voir là-dessus les références données supra, n. 17.

${ }^{105}$ Voir Mathieu Terrier, Histoire de la sagesse et philosophie shi'ite. L’Aimé des cœurs de Quṭb al-Dīn Aškevarī(Paris: Le Cerf, 2016).

${ }^{106}$ Voir Dimitri Gutas, « Sayings by Diogène preserved in Arabic », dans Marie-Odile Goulet-Cazé et Richard Goulet (éd.), Le cynisme ancien et ses prolongements (Paris : PUF, 1993), 475-518, repris dans Idem, Greek Philosophers in the Arabic Tradition (Aldershot : Ashgate Variorum, 2000), art. II ; M. Terrier, Histoire de la sagesse, 565-579.
} 
ce qui est rapporté dans les prières adressées à Dieu de la part des Impeccables [les imâms] : «Le bien est entre Tes mains mais le mal ne Te revient $\operatorname{pas}^{107}{ }^{10}$

Le sage antique se voit ainsi assimilé, de manière évidemment anachronique, aux «philosophes qadarites » qui, dans l'hérésiographie de Šahrastānī, désignent les théologiens mu'tazilites faisant du librearbitre humain un corrélat nécessaire de la Justice divine ( 'adl) - une doctrine partiellement passée dans le shi'isme, comme nous l'avons vu. C'est pour se voir attribuer une théodicée plus pieuse que philosophique. Le rapprochement de la maxime de Diogène avec le hadit tit attribué aux imâms shi'ites est caractéristique de la démarche d'Aškevarī cherchant à démontrer l'harmoniser ou la symphonia de la sagesse antique et de la science sacrée du Prophète et des imâms. L'idée se précise et se complexifie dans un passage emprunté au philosophe išrā qū - disciple de Šihāb al-Dīn Suhrawardī (m. 587/1191) - Šams al-Dīn al-Šahrazūrī (m. entre $687 / 1288$ et $704 / 1305)$ :

La démonstration de ceci, c'est que toutes les espèces de maux ne se trouvent que dans le monde de la génération et de la corruption, à cause de la contradiction (taḍādd) qui advient en lui, et [ces maux] sont infimes par rapport aux biens qui s'y trouvent. N'étaient-ce la génération et la corruption advenant dans ce monde par la contradiction, l'existence des âmes et des individus ne serait pas avérée, car les âmes ne naissent qu'au moment de la naissance des corps, étant disposées à se lier à eux, ce qui n'arrive que par l'interaction de modalités contraires. La contradiction advenant dans ce monde est cause de la continuité de l'Émanation; elle est donc un bienfait du point de vue de l'ordre universel, un mal du point de vue des individus particuliers.

La contradiction qui est la cause de la génération et de la corruption ne provient pas de l'opération d'un agent, mais fait partie des concomitants des quiddités. [...] Ces quiddités ont pour concomitant l'existence de la génération et de la corruption qui est la source du bien et de l'existence, dont s'ensuivent quelques maux mineurs au regard de ses biens et de ses bénéfices ${ }^{108}$.

Le mal se voit ici justifié par ce que Hegel appellera « le travail du négatif », la puissance productrice de la contradiction ; on peut aussi y entendre un écho de la Discorde (neikos) empédocléenne. Cette idée nouvelle se voit immédiatement associée à celle, déjà longuement rencontrée chez Mīr Dāmād, de maux mineurs concomitants à des biens majeurs. Aškevarī conclut d'ailleurs ce développement par une citation cachée de son ancien maître : «Tout ce qui reçoit l'existence dans le monde [de la possibilité] est subordonné au Décret et à la Détermination de Dieu. Les biens du monde dépendent de la Volonté [divine] et entrent dans le Décret par

107 Quṭb al-Dīn Aškevarī, Maḥbūb al-qulūb, al-maqāla al-ulā, éd. Ibrāhīm al-Dībāḡī et Hāmed Ṣidqī (Téhéran : Mīrāṭ-i maktūb, 1378 h.s./1999), 320 ; al-Šahrastānī, Milal, vol. 2, 15o, sauf la dernière phrase avec le hadītimâmite. On remarque qu'Aškevarī attribue celui-ci aux imâms shicites. Pour les références de ce hadīt, voir supra n. 96.

108 Aškevarī, Maḥbūb, 320-321; Šams al-Dīn Muḥammad b. Maḥmūd al-Šahrazūrī, Rasā'il al-Šăgarat al-ilāhīya fí 'ulūm alhaqā’iq al-rabbānīya, éd. Nağafqulī Ḥabībī, 3 vol. (Téhéran: Mo'assasa-ye pağūhašì hẹekmat o falsafe-ye Īrān, 1383 h.s./20045), vol. 3, 614-615. Sur ce passage, voir Terrier, Histoire de la sagesse, 565-566, 575-577. 
essence; les maux, eux, n'y entrent que par accident, en tant qu'ils sont les concomitants de biens innombrables et d'intérêts supérieurs» ${ }^{109}$.

L'explication conjugue le schème émanationniste néoplatonicien à la physique aristotélicienne pour conférer à la contradiction une fonction providentielle, celle d'assurer la continuité de l'Effusion première par le renouvellement infini des êtres. Inhérente au monde du devenir, la contradiction n'est ni l'acte ni l'objet de la Volonté divine elle-même mais la concomitance des quiddités créées immédiatement et éternellement par Dieu ; elle est par essence cause du bien, étant cause de l'existence en général, et par accident seulement cause des maux pour les individus particuliers.

Aškevarī revient sur le problème du mal dans sa notice sur Zoroastre. La présence du prophète du mazdéisme, religion couramment associée au dualisme théologique, dans une histoire islamique et shi'ite de la sagesse, est loin d'aller de soi, et notre auteur déploie tout son art de la symphonia pour la défendre. En revanche, que le problème du mal soit traité à cette occasion ne doit pas nous surprendre, le mazdéisme ayant sans doute été la première religion à l'avoir pris en charge par une théologie rationnelle ${ }^{110}$. Empruntant encore son rapport doxographique à Šahrastānī, Aškevarī dédouane Zoroastre de tout dualisme foncier en lui attribuant une théodicée paradoxale :

[Zoroastre] professa que la lumière et l'obscurité sont deux principes antagonistes, tout comme Yazdān [Ahura Mazda] et Ahriman. [La lumière et l'obscurité] sont l'origine des existants du monde, à partir de leur mélange ont été produites les compositions et à partir des compositions ont été innovées les formes. Le Seigneur Très-Haut est le Créateur et l'Instaurateur de la lumière et de l'obscurité. [...]. Il n'est pas permis de Lui attribuer l'existence de l'obscurité, mais le bien et le mal, l'intégrité et la corruption, la pureté et le vice, ne se produisent que par le mélange de la lumière et de l'obscurité. Si elles n'étaient pas mélangées, le monde n'aurait pas d'existence. Elles se combattront et s'affronteront jusqu'à ce que la lumière triomphe de l'obscurité et que le bien triomphe du mal. [...] C'est le Seigneur Très-Haut qui a mélangé et confondu [la lumière et l'obscurité] par la sagesse qu'll voyait dans la composition ${ }^{11}$.

Il y a manifestement une tension entre deux assertions : que «le Seigneur est le Créateur et l'Instaurateur de la lumière et de l'obscurité », et qu'il est impossible de faire remonter à Dieu-Yazdān l'existence de l'obscurité. La suite du texte tente de concilier les deux propositions en faisant de l'obscurité un concomitant de la lumière, ce qui entraîne logiquement le caractère second ou dérivé du mal :

\footnotetext{
${ }^{109}$ Aškevarī, Mạ̣būb, 320-321; Mīr Dāmād, Moqaddeme-ye Šări' al-nağăt, dans Muṣannafāt Mīr Dāmād, vol. 1, 571, cité supra.

${ }^{110}$ Voir Jean de Menasce, Škand-gumānīk vičâr : La solution décisive des doutes. Une apologétique mazdéenne du IX siècle, (Fribourg : Librairie de l'Université, 1945).

${ }^{111}$ Aškevarī, Mặbūb, 356-7.
} 
[Zoroastre] dit: «L'existence [de la lumière] est celle d'un principe. L'obscurité suit [la lumière] comme l'ombre suit l'individu. On la croit existante sans qu'elle le soit réellement. [Dieu] instaura la lumière et établit l'obscurité à sa suite, car la contradiction fait partie de la nécessité de l'existence. C'est pourquoi l'existence [de l'obscurité] est nécessaire, qu'elle a lieu d'être dans la création, mais non en première intention, comme le montre l'analogie avec l'individu et de son ombre ${ }^{112}$.»

Sont ainsi attribuées à Zoroastre les deux thèses philosophiques précédemment développées : le mal n'est qu'un concomitant accidentel du bien ; la contradiction est nécessaire au monde de la création. Aškevarī entreprend ensuite de sauver la conception mazdéenne de l'accusation de dualisme en citant, sans la nommer, un passage de la Risālat al-Ğāmi'a des Ihwwān al-Ṣafā', une œuvre d'inspiration néoplatonicienne et de tendance dogmatique ismaélienne, que l'on est étonné de voir utilisée par un auteur imâmite :

On pourrait éclaircir son discours [en disant] que le mal désigné par l'obscurité n'a pas son origine dans l'Instauration première (fí l-ibdā'al-awwal) venant de l'Instaurateur Vrai (al-mubdi' al-ḥaqq). En effet, le Bien universel ou l'Existence pure est l'effusion du Créateur (al-bāri') sur l'Intellect premier. Celui-ci possède la préséance, la complétude, la perfection et l'antériorité d'existence sur les choses. Puis l'Âme procéda de [l'Intellect] en le suivant. L'inégalité (tafạḍu) entre les deux consistait dans un rang inférieur de l'Âme incapable de rejoindre l'Intellect et une imperfection par rapport au niveau de celui-ci. [L'Âme] se trouva manquer de perfection et ce manque (taqșīr) se transforma en impuissance ('ă̆z). De cette impuissance advint une imperfection (naqș) l'empêchant d'atteindre l'Intellect universel. Puis la Nature procéda de l'Âme, laquelle est meilleure qu'elle du fait d'être un principe pour elle. L'inégalité entre les deux consistait en une impuissance [de la Nature] plus grande encore que celle de l'Âme à atteindre le rang de l'Intellect. Ensuite, les choses composées procédèrent les unes des autres. [...]

Il est donc avéré (...) que le mal n'a pas son origine dans l'Instauration. Ce n'est que l'impuissance des choses, advenue aux unes par les autres, qui a été appelée mal, au sens du retard empêchant la chose de rejoindre le niveau de l'être meilleur, antérieur [en existence] sur elle. Quand l'inférieur renonce à rejoindre le niveau de l'être meilleur, se satisfait pour lui-même d'être dans le lieu le plus abject et le plus vil, c'est là le mal pur éloigné de tout bonheur.

Ainsi, quand le monde recevra l'Effusion et la Libéralité [divines], quand il s'élèvera jusqu'à l'Intellect, il deviendra tout entier un bien. Le mal disparaîtra, la création retournera à son état primordial et deviendra tout entière un bien. Dieu dit : «De même que Nous avons instauré une création première, Nous recommençons à créer. Promesse à Notre charge, et Nous réalisons. » (Cor. 21:104) ». Quand le mal et son créateur (hāliquhu) se retireront, il n’y aura plus que le bien et son Créateur. Alors l'unicité de Dieu (tawhīd)

${ }^{112}$ Aškevarī, Maḥbūb, 357 ; source des deux extraits : al-Šahrastānī, Milal, part. 1, 217-218. 
sera établie, l'anthropomorphisme (tašbīh) et l'associationnisme (šark) disparaîtront, et il sera avéré que le mal n'a pas son origine dans l'Instauration [première $]^{113}$.

Dans une glose marginale, Aškevarī ramène cette théodicée mazdéenne à une tradition prophétique et imâmite déjà citée : «Sur le fait qu'il n'est pas permis de tenir pour le premier être instauré l'obscurité et le mal, mais seulement le bien, [alors que] le mal, l'intégrité et la corruption, ne se produisent que par le mélange de [la lumière et de l'obscurité], il est rapporté dans la prière transmise par des voies sûres : « Le bien est entre Tes mains mais le mal ne Te revient pas » ${ }^{114}$.

À la différence de Mullā Šamsā, Aškevarī reconnaît donc la présence du mal dans le monde, et même du mal pur comme refus du mouvement de perfectionnement, possibilité qui n'était pas envisagée jusqu'ici. C'est un écho du thème ismaélien du «drame dans le ciel » causé par l'inégalité des hypostases et ce que l'on peut appeler le «complexe d'infériorité » de l'Âme et de la Nature. Le mal, défini comme le retard pris par les existants dans leur retour à l'Origine, apparaît alors comme un événement accidentel et cependant constitutif de l'univers et de l'histoire. Cette conception permet au Pseudo-Zoroastre et à Aškevarī de dédouaner Dieu, Instaurateur du mélange, de toute responsabilité dans le mal historique. L'« Instauration véritable » des Ihwān al-Ṣafā’ se voit ainsi homologuée au «Décret primordial » de Mīr Dāmād. Cet emprunt étonnant à un texte d'inspiration ismaélienne permet ainsi de rejoindre une position fondamentale du shi'isme imâmite, soutenue par Mīr Dāmād dans son essai sur le badā': tout le mal historique n'est qu'un retard dans l'accomplissement de la sage Volonté divine, soit le règne de l'Imâm sur terre ; il n'est qu'un accident, inséparable de l'histoire mais finalement passager.

C'est encore en conformité avec la doctrine imâmite qu'Aškevarī, toujours suivant Zoroastre, trouve finalement la clé de la théodicée dans une historiosophie de la Fin des temps. À la fin de sa notice, il identifie en effet l'Homme providentiel et Sauveur eschatologique du mazdéisme, le troisième Saošyant appelé AstvatEreta, au Mahdī du shi'isme, le douzième imâm attendu pour « couvrir la terre de justice comme elle l'aura été d'injustice $»^{115}$. La théodicée d'Aškevarī reconduit ainsi, via l'apologie ouverte du mazdéisme et une réhabilitation masquée de l'ismaélisme, aux sources du shicisme imâmite, dont la dimension messianique paraissait sciemment évacuée dans les essais de Mīr Dāmād et de Mullā Šamsā.

\section{Conclusion}

\footnotetext{
${ }^{113}$ Aškevarī, Maḥbūb, 357-358 ; Ihwān al-ṣafā', al-Risāla al-Ğāmi'a, éd. Mușțafā Gaālib (Beyrouth: Dār al-Andalus, 1404/1984), 49-5o, citation modifiée par endroits. La dernière phrase est d'Aškevarī ou d'une autre source. Voir sur ce passage Daniel De Smet, « «Le mal ne s'enracine pas dans l'instauration». La question du mal dans le shíisme ismaélien» dans ce dossier.

${ }^{114}$ Aškevarī, Mahbūb al-qulūb, ms. n ${ }^{4889}$, Bibliothèque centrale de l'Université de Téhéran, 195.

${ }^{115}$ Aškevarī, Mạ̣būb, 359. Sur cet extrait, voir Henry Corbin, « L'idée du Paraclet en philosophie iranienne », Face de Dieu,

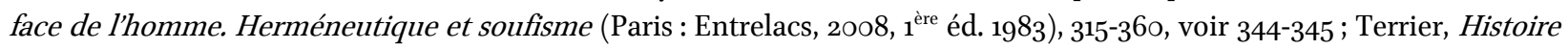
de la sagesse, $643-646$.
} 
Si l'entreprise d'une théodicée comme résolution philosophique et théologique du problème du mal est si délicate dans le shicisme imâmite, pourquoi autant d'essais dans l'Iran safavide du $\mathrm{XI}^{\mathrm{e}} / \mathrm{XVII}^{\mathrm{e}}$ siècle ? Il s'agit d'abord, selon le projet de Mīr Dāmād, de faire de la philosophie la science de la Sagesse divine, autrement dit la vraie théologie, sans laisser aux juristes (fuqahāe) et traditionnistes (muḥadditūun) les problèmes fondamentaux de la foi, à commencer par celui du mal dans la création et l'histoire. Si Mīr Dāmād tient à affronter à la fois les paradoxes théoriques des hadịts imâmites et les difficultés pratiques de l'application de la Loi, c'est bien en tant que philosophe, avec les ressources du raisonnement et du concept, qu'il entend le faire. Parmi ses deux élèves, Mullā Šamsā s'émancipe de toute référence ou presque à la tradition imâmite tandis qu'Aškevarī renoue avec celle-ci en s'éloignant de la nouvelle orthodoxie uṣūlīe et du rationalisme de son maître. Mais il s'agit aussi, pensons-nous, de rendre raison d'une situation historique vécue par la conscience shi'ite. L'avènement du shi'isme imâmite comme religion d'État en Iran (906/15o1) était né d'une foi messianique en la délivrance (farağ) imminente, censée réparer et détruire tout le mal de l'histoire. Mais après plus d'un siècle, malgré la puissance du royaume sous Šāh 'Abbās, le mal semblait plus que jamais présent, sous toutes ses formes : le mal physique des épidémies et des séismes; le mal politique des guerres à répétition contre l'empire ottoman voisin (et l'impuissance militaire constatée notamment à la bataille de Chaldiran en 1514); le mal doctrinal des croyances dévoyées, extérieures ou intérieures au shi'isme, résistant à toute politique religieuse de conversion et de pacification; le mal moral de la corruption et de la licence, répandu du sommet de l'État à la basse populace. Le mal historique des origines n'était aucunement racheté

par l'état présent du pouvoir et de la religion, et la tentation messianique demeurait vive. Les philosophes étudiés ici se sont employés à subsumer ces maux, pour les dissoudre, sous la conception métaphysique du mal comme imperfection, puissance (opposée à l'acte) et inexistence. On ne saurait donc se satisfaire d'une explication historiciste de ces essais de théodicée dans l'Iran safavide du XI $/ \mathrm{XVII}^{\mathrm{e}}$ siècle, comme on ne saurait y voir l'expression pure d'une philosophia perennis. Reste à souligner une évidence : le défi que le problème du mal représente pour la pensée a joué un rôle majeur dans l'histoire des idées philosophiques, en terre d'Islam comme en Europe, et en particulier dans l'Iran shicite du XI $/ \mathrm{XVII}^{\mathrm{e}}$ siècle.

\section{Bibliographie}

\section{Sources primaires étudiées :}

Aškevarī, Quṭb al-Dīn. Maḥbūb al-qulūb, al-maqāla al-ulā. Éd. Ibrāhīm al-Dībāğ̄i et Ḥāmid Ṣidqī. Téhéran : Mīrāt-e maktūb, 1378 h.s./1999.

Aškevarī, Quṭb al-Dīn. Mạ̣būb al-qulūb, ms. n 4889, Bibliothèque centrale de l'Université de Téhéran.

Mīr Dāmād. Kitāb al-qabasāt. Éd. Mahdī Moḥaqqeq. Téhéran : Mo'assasa-ye entešārāt va čāp-e dānašgāh-e Tehrān, 1395 h.s./2016 (1 ${ }^{\text {ère }}$ éd. 1977).

Mīr Dāmād. Muqaddima Risāla Shāri‘ al-nağăt. Dans Muṣannafāt Mīr Dāmād, ğild-e avval. Éd. 'Alī Nūrānī. Téhéran : Anğoman-e ātār va mafāherer-e farhangī, 1381 h.s./2003, 568-580.

Mīr Dāmād. Risālat al-Īqāzāt fì hualq al-a'māl. Éd. Ḥāmed Nağī Esfahānī. Téhéran: Mo’assasa pağūhaši-ye h.̣ekmat o falsafeh, 1391 h.s./2012-3. 


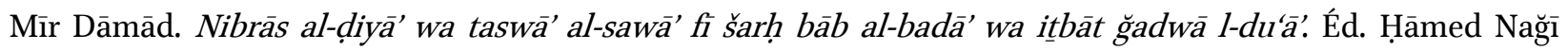
Esfahānī. Téhéran : Mīrāte-e maktūb, 1374 h.s./1995.

Mullā Šamsā Gīlānī. Ižhār al-kamāl. Dans Anthologie des philosophes iraniens du XVIT jusqu'à nos jours. Éd. Seyyed Ğalāloddīn Āštiyānī, 4 vols.. Téhéran-Paris : Institut Français de Recherche en Iran - Librairie d'Amérique et d'Orient Adrien-Maisonneuve, 1972-1978, vol. 1, 437-446.

\section{Autres sources}

Al-Bağdādī, 'Abd al-Qāhir. Al-Farq bayn al-firaq wa bayan al-firqa al-nāğiya minhum. Éd. s.n.. Beyrouth : Dār alafaq, $1408 / 1987$.

Bahmanyār b. Mazarbān. Kitāb al-Taḥ̣̣̂ll. Éd. Murtaḍā Muț̣aharī. Téhéran : Entešārāt-e dānašgāh-e Tehrān, 1375 h.s./1996-7.

al-Barqī, 'Alī b. Muḥammad. Kitāb al-Mạhāsin. Éd. Mahdī al-Rağā̄ì, 2 vols.. Téhéran : al-Mağma' al-ālamī li-ahl al-bayt, Téhéran, 1432/2011.

Épictète. Entretiens. Trad. fr. Jean Souilhé. Paris : Gallimard-Tel, 1993.

Fayḍ Kāšānī, Muḥammad Muḥsin. Kitāb al-Wāfi. Éd. s.n., 26 vols.. Ispahan : Ketābhāane-ye Imām Amīr almu'minīn 'alayhi l-salām, 1406/1985-6.

Ḥurr 'Amilī, Muḥammad b. Ḥasan. Wasā’il al-š̌̃ăa. Éd. coll., 30 vols.. Qum : Mu’assasat Āl al-bayt 'alayhim alsalām, 1409/1988-9.

Ibn Bābūya (Šayḩ Ṣadūq). Kitāa al-Tawḥìd. Éd. s.n.. S.l. : Dār al-aḍ̂ā', 1430/2009.

Ibn Sīnā. Ilāhiyyāt al-Šifầ. Éd. al-Ab Qanawātī et Sa'īd Zāyid. Beyrouth : s.n., 196o.

Ibn Sīnā. Al-Išārāt wa-l-tanbīhāt. Éd. Muğtabā Zāri'ī. Qum : Bostān-e ketāb, 1387 h.s./20o8-9.

Avicenne. Livre des directives et des remarques. Trad. fr. Amélie-Marie Goichon. Paris : Vrin, 1999, $1^{\text {ère }}$ éd. 1951.

Ibn Sīnā. Al-Ta Iīqāt. Éd. 'A. Badawī. Beyrouth: Maktabat al-i'ām al-islāmī, 1404/1983-4.

Ibn Sīnā. Al-Talīqāt. Éd. Ḥusayn Mūsaviyān. Téhéran : Mo’assasa pağūhaši-ye ḥekmat o falsafe-ye Īrān, 1391 h.s./2012-3.

Ihwwān al-ṣafā'. Al-Risāla al-Ğāmi'a. Éd. Mușțafā Ġālib. Beyrouth : Dār al-Andalus, 1404/1984.

Al-Kulaynī, Muḥammad b. Ya'qūb. Ușūl al-Kāfì. Éd. s.n.. Beyrouth : Mu’assasat al-a'lamī li-l-maṭbū'āt, 1426/2005.

Leibniz. Essais de théodicée. Paris : Garnier-Flammarion, 1969.

Al-Mağlisī, Muḥammad Bāqir. Bị̣ār al-anwār. éd. coll., 111 vol.. Beyrouth : Dār al-turāt al-'arabī, 1403/1983.

Al-Nu'mānī, Ibn Abī Zaynab Kitāb al-Ġayba. Éd. Muḥammad Ğawād Ġaffārī. Téhéran: Dār al-kutub alislāmiyya, 139o h.s./2011-2.

Al-Rāzī, Faḩr al-Dīn. Šarḥ al-Išārāt. Éd. s.n., 2 vol.. Qom : Maktabat Āyatullāh Mar'ašī, 1404/1983-4.

Ricœur, Paul. Le mal. Un défi à la philosophie et à la théologie. Genève : Labor et fides, 2004. 
Al-Ṣaffār al-Qummī (m. 29o/902-3), Bașā'ir al-darağăt. Éd. 'Alīreḍā Zakīzādeh Rinānī, 2 vol.. Qom : Wuṭūq, 1391 h.s./2012-3.

Spinoza. Éthique. Trad. fr. Bernard Pautrat. Paris : Le Seuil, 2010.

Al-Šahrastānī, Abū l-Fatḥ Muḥammad b. 'Abd al-Karīm. Kitāb al-Milal wa l-nị̣al. Éd. Muḥammad b. Fatḥallāh Badrān, 2 vols.. Le Caire : Maktabat al-anglūl-mișrīya, vol. 1 1366/1947, vol. 2 1375/1955.

Al-Šahrazūrī, Šams al-Dīn Muḥammad b. Maḥmūd. Rasāỉl al-Šăgarat al-ilāhīya fì 'ulūm al-ḥaqāíq al-rabbānīya. Éd. Nağafqulī Ḥabībī, 3 vols.. Téhéran : Mo'assasa-ye pağūhašī ḥekmat o falsafe-ye Īrān, 1383 h.s./20045 .

Al-Ṭabarsī, al-'Allāma. Al-Iḥtiğăăğ. Éd. Ibrāhīm Bahādarī et Muhammad Hādībeh, 2 vols.. Qom : Uswa, 1413/19923 .

Al-Ṭabarsī, Abū 'Alī al-Faḍl b. al-Ḥasan. Mağma' al-bayān fì tafsìr al-Qur'ān. Éd. Hāšim al-Rasūlī al-Mahallātī, 5 vols.. Beyrouth : Dār Ihỵā’ al-turāț al-'arabī, 1379/1339 h.s./196o-1.

Al-Ṭūsī, Naṣīr al-Dīn. Šarh al-Išārāt wa-l-tanbīhāt. Éd. s.n., 3 vols.. Qom : Našr al-balāg̉a, 1375 h.s./1996-7.

Al-Ṭūsī, Nașīr al-Dīn. Talhịṣ al-Muḥașșal. Éd. 'Alī Nūrānī. Téhéran : Mu’assasa muṭāla'āt islāmī ğāmi'at Māk Gīl wa ğāmi‘a Tihrān, 1359 h.s./198o.

Études :

Amir-Moezzi, Mohammad Ali. La preuve de Dieu. La mystique shi'ite à travers l'œuvre d'al-Kulaynî (IX ${ }^{e}-X^{e}$ siècle). Paris : Le Cerf, 2018.

Amir-Moezzi, Mohammad Ali. Le Coran silencieux et le Coran parlant. Sources scripturaires de l'islam entre histoire et ferveur. Paris : CNRS éditions, 2011.

Amir-Moezzi, Mohammad Ali. Le guide divin dans le shîisme originel. Aux sources de l'ésotérisme en islam. Lagrasse : Verdier, 2007, ${ }^{\text {ère }}$ éd. 1992.

Amir-Moezzi, Mohammad Ali, et Jambet, Christian. Qu'est-ce que le shi'isme ?. Paris : Fayard, 2004.

Amir-Moezzi, Mohammad Ali. « Badā’ ». Encyclopaedia of Islam, $3{ }^{\mathrm{e}}$ éd.. Éd. Kate Fleet et alii. Consulté en ligne le 22 octobre 2018 <http://dx.doi.org/10.1163/1573-3912_ei3_COM_25083>

Arjomand, Said Amir. The Shadow of God and the Hidden Imam. Chicago - Londres: The University of Chicago Press, 1984.

Corbin, Henry. La philosophie iranienne islamique aux XVII et XVIIT siècles. Paris : Buchet-Chastel, 1981.

Corbin, Henry. «L'idée du Paraclet en philosophie iranienne». Dans Face de Dieu, face de l'homme. Herméneutique et soufisme. Paris : Entrelacs, 2008 (1 ère éd. 1983), 315-36o.

De Smet, Daniel. « «Le mal ne s'enracine pas dans l'instauration». La question du mal dans le shíisme ismaélien ». Oriens.

Ess, Joseph Van. « Kadariyya ». Encyclopédie de L'islam, deuxième édition. Vol. IV, 384-388. 
Guiraud, Morgan. «Destin». Dans Dictionnaire du Coran. Mohammad Ali Amir-Moezzi (dir.). Paris : Robert Laffont, 2007, 209-212.

Gutas, Dimitri. «Sayings by Diogène preserved in Arabic ». Dans Le cynisme ancien et ses prolongements, Marie-Odile Goulet-Cazé et Richard Goulet (éd.), Paris : PUF, 1993, 475-518. Repris dans Idem. Greek Philosophers in the Arabic Tradition. Aldershot : Ashgate Variorum, 2000, art. II.

Izutsu, Toshihiko. « Mîr Dâmâd and his Metaphysics ». Dans Mīr Dāmād, Kitāb al-Qabasāt. Introduction, p. 1-15.

Jambet, Christian. La fin de toute chose, suivi de l'Épître du Rassemblement de Mullâ Sadrâ. Paris : Albin Michel, 2017 .

Madelung, Wilferd. « Badā’». Encyclopaedia Iranica, Vol. III, Fasc. 4. Éd. Ehsan Yarshater. Boston: Routledge and Kegan Paul, 1988, 354-355.

Mazzaoui, Michel M.. The Origins of the Safawids (Shi'ism, Sufism and the Ghulât). Wiesbaden : Franz Steiner, 1972.

De Menasce, Jean. Škand-gumān̄̄k vičâr : La solution décisive des doutes. Une apologétique mazdéenne du IX siècle. Fribourg : Librairie de l'Université, 1945.

Murad, Hasan Qasim. «Jabr and Qadar in Early Islam: A Reappraisial of their Political and Religious Implications ». Dans Islamic Studies Presented to Charles J. Adams. Wael Hallaq et Donald Little (éd.). Leiden, Brill : 1991, 117-132.

Ormsby, Eric. Theodicy in Islamic Thought: the Dispute over al-Ghazali's Best of All Possible Worlds. Princeton : Princeton University Press, 1984.

Parsapajouh, Sepideh. « Le mal subi, le mal rendu. Une lecture anthropologique des pratiques de lamentations et de malédictions dans le shicisme populaire iranien ». Oriens.

Rahman, Fazlur. «Mīr Dāmād's Concept of ḥudūth dahrī: A Contribution to the Study of God-World Relationship Theories in Safavid Iran », Journal of Near Eastern Studies 39, 2 (1980) : 139-151.

Rizvi, Sajjad H.. «Between Time and Eternity: Mīr Dāmād on God's Creative agency ». Journal of Islamic Studies 17:2 (2006) : 158-176.

Rizvi, Sajjad. «Mullā Shamsā Gīlānī and his Treatise on the Incipience of the Cosmos (ḥudūth al-ālam) ». Ishraq (Islamic Philosophy Yearbook) 6 (Moscou : Nauka - Vostochnaya Literatura, 2015), 40-70

Rizvi, Sajjad. « Considering Divine Providence in Mullā Șadrā Šīrāzī (d. 1045/1636): The Problem of Evil, Theodicy, and the Divine Eros ». Oriens.

Shihadeh, Ayman. "Avicenna's Theodicy and al-Rāzīs Anti-Theodicy », Intellectual History of the Islamicate World, 7 (2019) : 61-84.

Terrier, Mathieu. Histoire de la sagesse et philosophie shi'ite. L'Aimé des cœurs de Quṭb al-Dīn Aškevarī. Paris : Le Cerf, 2016. 
Terrier, Mathieu. «De l'éternité ou de la nouveauté du monde: parcours d'un problème philosophique d'Athènes à Ispahan ». Journal Asiatique 299.1 (2011) : 369-421.

Terrier, Mathieu. «Anthropogonie et eschatologie dans l'œuvre de Muḥsin Fayḍ Kâshânî : l'ésotérisme shîiite entre tradition et syncrétisme». Dans L'ésotérisme shîite, ses racines et ses prolongements/Shi'i Esotericism : its roots and developments. Mohammad Ali Amir-Moezzi (dir.). Turnhout : Brepols, 2016, 743-780.

Terrier, Mathieu. «The Wisdom of God and the Tragedy of History: the Concept of Appearance (badā) in Mīr Dāmād's Lantern of Brightness». Dans Philosophy and the Intellectual Life in Shīah Islam. Saiyhad Nizamuddin Ahmad et Sajjad Rizvi (éd.). Bloomsbury : The Shīah Institute Press, 2017, 94-134.

Terrier, Mathieu. «Le combat sacré des vaincus de l'histoire : expérience et représentation du jihād dans le shi'isme imamite ancien ». Journal Asiatique 305.1 (2017) : 23-31.

Terrier, Mathieu. « Mīr Dāmād (m. 1041/1631), philosophe et mujtahid. Autorité spirituelle et autorité juridique en Iran safavide shīite ». Studia Islamica 113 (2018) :121-165.

Terrier, Mathieu. «La Rétribution finale en islam : discussions sur l'imputation des actes et la perpétuité des peines ». Dans 'Retribution' in Jewish and Christian Writings: a Concept in Debate. David Hamidovic, Apolline Thromas et Matteo Silvestrini (dir.). Tübingen : Mohr Siebeck, 2019, 123-148.

Terrier, Mathieu. «De l'ésotérisme shi'ite à la philosophie shi'ite. Mullā Ṣadrā, Mīr Dāmād et la question du badā’». Dans Raison et quête de la sagesse. Hommage à Christian Jambet. Mohammad Ali AmirMoezzi (dir.). Turnhout : Brepols, 2021, 507-55०. 